\title{
Self-Redirection of Metabolic Flux toward Squalene and Ethanol Pathways by Engineered Yeast
}

\author{
Robina Manzoor ${ }^{1}$, Maqbool Ahmed ${ }^{2}$, Naveeda Riaz ${ }^{3}{ }^{(1)}$, Bushra Hafeez Kiani ${ }^{3}$, Ullah Kaleem ${ }^{4}$, \\ Yasmeen Rashid ${ }^{5}$, Ali Nawaz ${ }^{6} \oplus$, Muhammad Umer Farooq Awan ${ }^{7}$, Hooria Khan ${ }^{8}$, \\ Umera Imtiaz ${ }^{6}$, Yasir Rasheed ${ }^{8}$, Imdad Kaleem ${ }^{8, *}$ and Aamir Rasool ${ }^{9,10, *}$ \\ 1 School of Life Science, Beijing Institute of Technology, Beijing 100081, China; 3820150009@bit.edu.cn \\ 2 Department of Tuberculosis, Bolan University of Medical and Health Sciences, Quetta 87300, Pakistan; \\ maqboola93@gmail.com \\ 3 Department of Biological Sciences, International Islamic University, Islamabad 45550, Pakistan; \\ Naveeda.riaz@iiu.edu.pk (N.R.); bushra.hafeez@iiu.edu.pk (B.H.K.) \\ 4 Department of Microbiology, University of Balochistan, Quetta 87300, Pakistan; \\ kaleem.mandokhail@gmail.com \\ 5 Department of Biochemistry, University of Karachi, Karachi 75530, Pakistan; Yrasid2004@yahoo.com \\ 6 Department of Industrial Biotechnology, Government College University, Lahore 53801, Pakistan; \\ ali.nawaz@gcu.edu.pk (A.N.); umii.imtiaz@gmail.com (U.I.) \\ 7 Department of Botany, Government College University, Lahore 53801, Pakistan; \\ dr.umerfarooqawan@gcu.edu.pk \\ 8 Department of Bioscience, COMSATS Institute of Information Technology (CIIT), Islamabad 45550, Pakistan; \\ hooriakhan.pk@gmail.com (H.K.); ginaaphoomichu40@gmail.com (Y.R.) \\ 9 Institute for Synthetic Biosystem, School of Chemistry and Chemical Engineering, Beijing Institute of \\ Technology, Beijing 100081, China \\ 10 Institute of Biochemistry, University of Balochistan, Quetta 87300, Pakistan \\ * Correspondence: kaleem.imdad@comsats.edu.pk (I.K.); rasool.amir@bit.edu.cn (A.R.); \\ Tel.: +92-3344448241 (I.K.); +86-17601640790 (A.R.)
}

Received: 18 December 2019; Accepted: 30 January 2020; Published: 1 February 2020

check for updates

\begin{abstract}
We have previously reported that squalene overproducing yeast self-downregulate the expression of the ethanol pathway (non-essential pathway) to divert the metabolic flux to the squalene pathway. In this study, the effect of co-production of squalene and ethanol on other non-essential pathways (fusel alcohol pathway, FA) of Saccharomyces cerevisiae was evaluated. However, before that, 13 constitutive promoters, like IRA1p, PET9p, RHO1p, CMD1p, ATP16p, USA3p, RER2p, COQ1p, RIM1p, GRS1p, MAK5p, and BRN1p, were engineered using transcription factor bindings sites from strong promoters HHF2p ( -300 to $-669 \mathrm{bp}$ ) and TEF1p ( -300 to $-579 \mathrm{bp}$ ), and employed to co-overexpress squalene and ethanol pathways in S. cerevisiae. The FSE strain overexpressing the key genes of the squalene pathway accumulated $56.20 \mathrm{mg} / \mathrm{L}$ squalene, a 16.43-fold higher than wild type strain (WS). The biogenesis of lipid droplets was stimulated by overexpressing DGA1 and produced $106 \mathrm{mg} / \mathrm{L}$ squalene in the FSE strain. AFT1p and CTR1p repressible promoters were also characterized and employed to downregulate the expression of ERG1, which also enhanced the production of squalene in FSE strain up to 42.85- (148.67 mg/L) and 73.49-fold (255.11 mg/L) respectively. The FSE strain was further engineered by overexpressing the key genes of the ethanol pathway and produced $40.2 \mathrm{mg} / \mathrm{mL}$ ethanol in the FSE1 strain, 3.23-fold higher than the WS strain. The FSE1 strain also self-downregulated the expression of the FA pathway up to $73.9 \%$, perhaps by downregulating the expression of GCN4 by 2.24-fold. We demonstrate the successful tuning of the strength of yeast promoters and highest coproduction of squalene and ethanol in yeast, and present GCN4 as a novel metabolic regulator that can be manipulated to divert the metabolic flux from the non-essential pathway to engineered pathways.
\end{abstract}


Keywords: Sacharomyces cerevisiae; engineered promoters; repressible promoters; squalene; fusel alcohol; ethanol

\section{Introduction}

Squalene is a polyunsaturated triterpenoid that acts as a precursor for the biosynthesis of steroids and cholesterol in animals and plants [1,2]. Several terpenoid synthases use squalene as a substrate to synthesize various types of triterpenoids including $\alpha$-amyrin, $\beta$-amyrin, and lupeol $[3,4]$. Squalene is used in many cosmetic products because it acts as an emollient, antioxidant, and moisturizing agent [5,6]. Squalene has also been approved as a cardioprotective [7] and radioprotective agent [8].

The large proportion of squalene is extracted from the liver of sharks to fulfill the industrial demand [9]. However, the constant supply of the squalene is at risk due to the sharp decline in the number of sharks and international concern regarding the protection of marine wildlife $[10,11]$. Saccharomyces cerevisiae can accommodate squalene in the lipid droplets, microsome, and void spaces of the plasma membrane [12,13]. This makes it an ideal candidate for industrial-scale production of squalene. Earlier, our engineered S. cerevisiae produced $\sim 304.16 \mathrm{mg} / \mathrm{L}$ squalene in the shake flask using terbinafine, an inhibitor of squalene epoxidase [14] and synergistically downregulated the expression of ethanol production pathway [15]. This indicates that yeast can self-redirect the metabolic flux from a non-essential pathway to an engineered pathway to alleviate the metabolic burden on pathways critical for its growth [15].

Ethanol also harbors many industrial applications, such as it is used in the preparation of a variety of beverages and consumed by the transport sector as a biofuel [16]. Yeast is also in practice for eight millennia for the production of a variety of alcoholic beverages [17]. Fermenting yeast not only excrete ethanol in the growth medium but also excrete several other low-molecular-weight compounds collectively termed as fusel alcohol [18]. Ethanol production is not necessary for the survival of yeast, because inhibition of its biosynthesis does not affect yeast growth $[19,20]$. S. cerevisiae produces fusel alcohol of different carbon chain length depending upon the type of substrates, such as it produces 2-Phenylethanol, tyrosol, and tryptophol through transamination and decarboxylation of phenylalanine, tyrosine, and tryptophan [18]. Yeast consumes one mole of NADH and excretes another mole of carbon for the production of one mole of ethanol, but it can re-metabolize ethanol in the subsequent growth phases [15]. On the other hand, yeast consumes one mole of ATP and $\mathrm{NADH}$ and excretes another one mole of $\mathrm{CO}_{2}$ for the production of one mole of fusel alcohol [18]. However, it cannot re-metabolize the excreted fusel alcohol to fulfill its energy requirements during the late exponential and stationary phases. A study has reported the overproduction of naringenin by deleting the byproduct forming genes including, Aro10, Pdc5, and $P d c 6$ of fusel alcohol pathway without affecting the growth rate of engineered yeast [21]. This endorses our hypothesis that the fusel alcohol pathway is not-essential for S. cerevisiae, and it can be manipulated for redirection of metabolic flux to the engineered pathways the same as the ethanol production pathway.

In this study, S. cerevisiae was engineered with squalene and ethanol production pathways to determine their coordinated effect on the expression and production of the fusel alcohol pathway. Promoter engineering is a useful strategy adopted to optimize the expression of genes of the engineered pathway for the overproduction of high-value compounds [22]. Therefore, the strength of our earlier characterized 13 yeast constitutive promoters was tuned using transcription factor binding sites (TFBS) from strong promoters HHF2p (-300 to $-669 \mathrm{bp}$ ) and TEF1p (-300 to $-579 \mathrm{bp}$ ) and subsequently employed to overexpress the squalene and ethanol production pathways in S. cerevisiae [14].

Expression of target genes can be regulated by using repressible promoters and therefore often employed to control the expression of genes competing for precursors with engineered pathways [23]. In this study, two novel metal ion repressible promoters AFT1p (iron) and CTR1p (copper) were also characterized and used to downregulate the expression of ERG1 for squalene overproduction in yeast. 
Squalene and ethanol pathways were co-overexpressed in Saccharomyces cerevisiae using engineered constitutive promoters for squalene and ethanol co-production. Metal ion repressible promoters were used to optimize the production of squalene, and determined the synergistic effect of squalene and ethanol co-overproduction on the expression of fusel alcohol pathway (Figure 1).

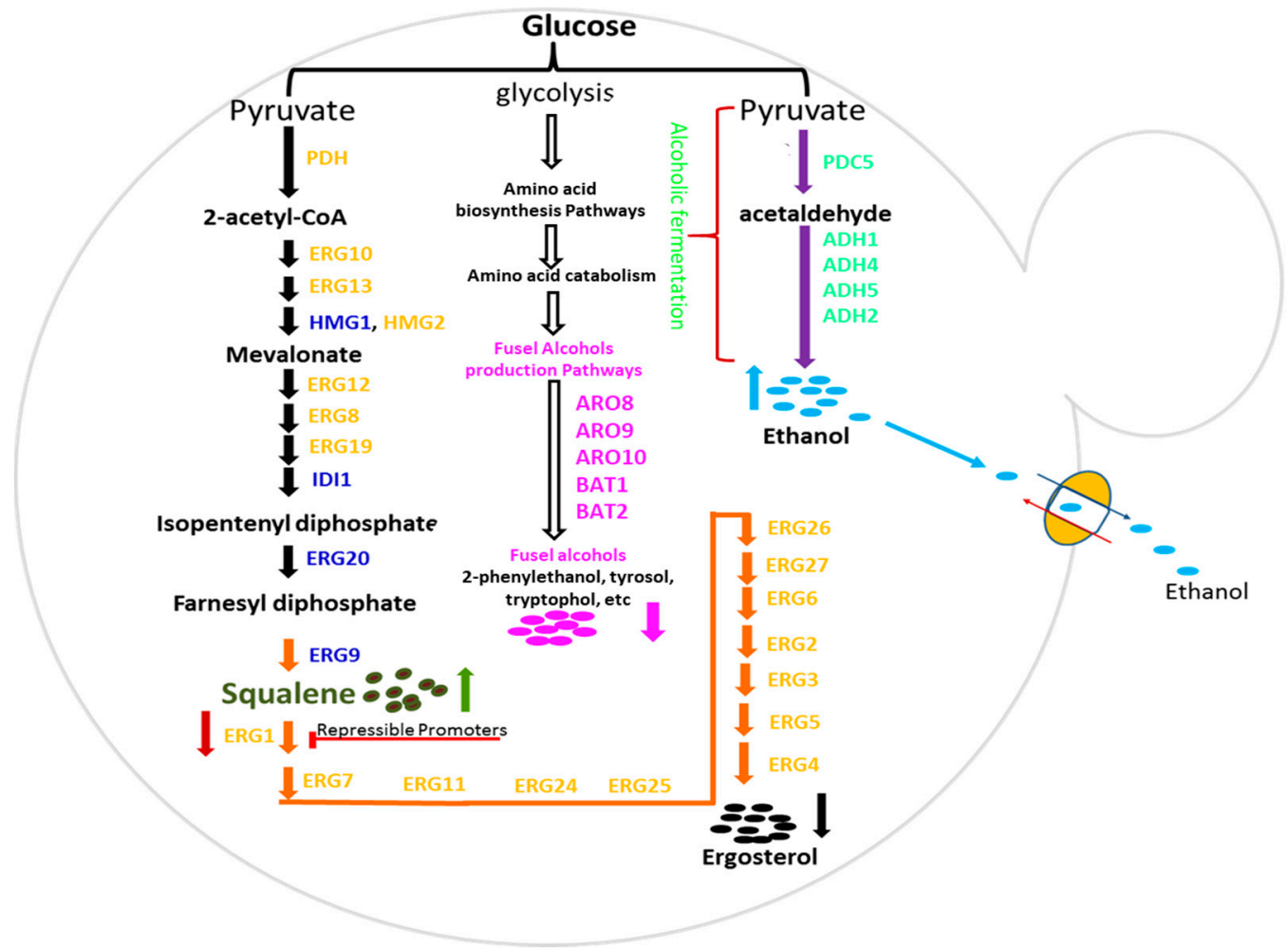

Figure 1. Engineering scheme of FSE1 strain: Engineered strain was constructed by co-overexpressing the vital genes of squalene and ethanol production pathways. Overexpressed genes of squalene and ethanol production pathways are written in blue and green, respectively. Auto-downregulated genes of the fusel alcohol production pathway are mentioned in purple.

\section{Results and Discussion}

\subsection{Tuning the Strength of Yeast Promoters}

Robust and balanced expression of the genes is a prerequisite for the successful overproduction of high-value compounds in engineered microbes [24,25]. This can be achieved using strong and well-characterized constitutive promoters capable of producing a higher titer of the enzymes robustly converting the substrate into the final product [26]. Although the repertoire of yeast constitutive promoters is large enough to engineer the medium size metabolic pathway, this repertoire does not possess a large number of strong promoters [27-29]. Only a few studies have reported the successful use of weak promoters and low copy plasmids to optimize the expression of the pathway to produce high-end products including, the precursor of Taxol in E. coli [30]. Transcription factors control the strength of promoter by regulating the binding of RNA polymerase on the core promoter through binding at the transcription factor binding sites (TFBS) present upstream of the core promoter. Thus composition and hierarchy of TFBS upstream of the core promoter regulate the strength of the promoter [22]. The previous report has shown that strength of strong constitutive promoter (GPDp) and strong inducible promoters $(G A L p)$ can be further enhanced by adding the enhancer element sequences upstream of core promoter acting as synthetic transcriptional amplifiers [22]. In this study, the strength of previously characterized constitutive promoters is tuned by adding the TFBS from strong promoters (Figure 2a) [14]. Transcription factor binding sequences from TEF1p (-300 to -579 bp) 
and HHF $2 p$ (-300 to $-669 \mathrm{bp}$ ) promoters were fused upstream of HHF2p, IRA1p, RHO1p, PET9p, CMD1p, ATP16p, USA3p, RER2p, COQ1p, RIM1p, GRS1p, MAK5p and BRN1p (Figure 2b,c, Table S6) and resulting promoters have been listed in the Table $S 6$. The strength of all aforementioned promoters after ligating the TFBS was reckoned via measuring the fluorescence intensity and mRNA level of enhanced green fluorescent protein (EGFP) and catalytic activity of $\beta$-galactosidase.

The strength of HHF2p, IRA1p, RHO1p, PET9p, CMD1p, ATP16p, USA3p, RER2p, COQ1p, RIM1p, GRS1p, MAK5p and BRN1p was increased by 56.39\%, 101.7\%, 95.51\%, 164.89\%, 108.69\%, 97.63\%, $96.49 \%, 81.53 \%, 63.21 \%, 24.48 \%, 21.49 \%, 21.322 \%$, and $27.45 \%$, respectively after adding the TFBS - TEF1 (Figure 2b, Table S6). The strength of HHF2p, IRA1p, RHO1p, PET9p, CMD1p, ATP16p, USA3p, RER2p, COQ1p, RIM1p, GRS1p, MAK5p and BRN1p was enhanced by 36.88\%, 59.69\%, 51.43\%, 100.42\%, 92.52\%, $85.74 \%, 76.36 \%, 80.75 \%, 48.53 \%, 26.467 \%, 23.89 \%, 42.46 \%$, and $50.57 \%$, respectively after attaching the TFBS-HHF2 (Figure 2c, Table S6). The strength of all promoters was enhanced to a different level by adding the TFBS of TEF1p and HHF2p (Figure 2b,c, Figure S5a-c). The increase above in the strength of engineered promoters was measured using an increase in fluorescence intensity of EGFP compared to the wild type promoters (Table S5). TFBS upstream of wild type promoters did not inflict adverse effect on the constitutiveness of wild type promoters, and this is also evident from the strong the induction of fluorescent intensity, mRNA level of EGFP and catalytic activity of $\beta$-galactosidase without an inducer by engineered promoters compared to the wild type promoters (Figure $2 b, c$ and Figure S5a-c). Yeast cells expressing EGFP downstream of engineered promoters are brighter than yeast cells expressing EGFP downstream of wild type promoters during confocal microscopy analysis keeping the analysis time fixed to $100 \mathrm{~ms}$ for each sample (Figure S5a-c).

The results of this study indicate that the strength of yeast constitutive promoters can be enhanced using TFBS of strong promoters. Moreover, the strength of the promoters can also be in-situ tuned by using multiplex gRNA carrying TFBS in the CRISPR-Cas9 system [31].

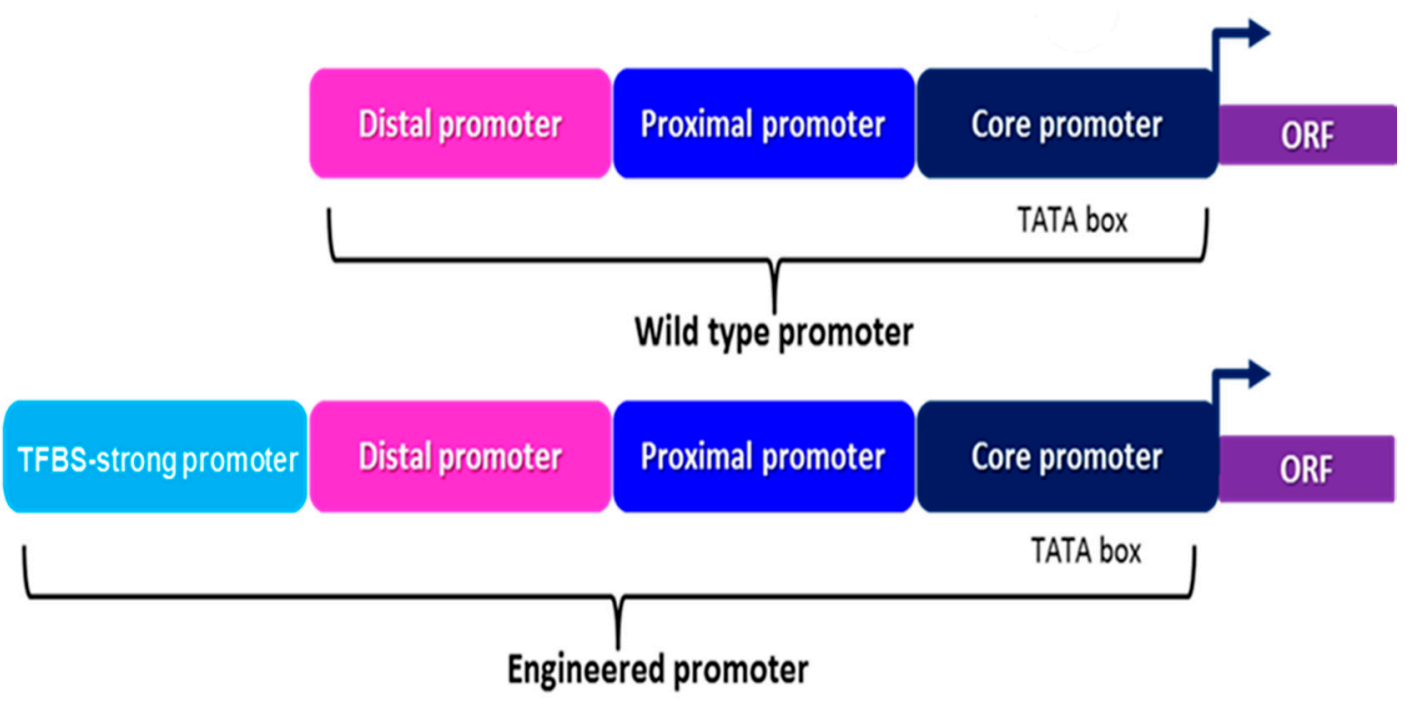

(a)

Figure 2. Cont. 


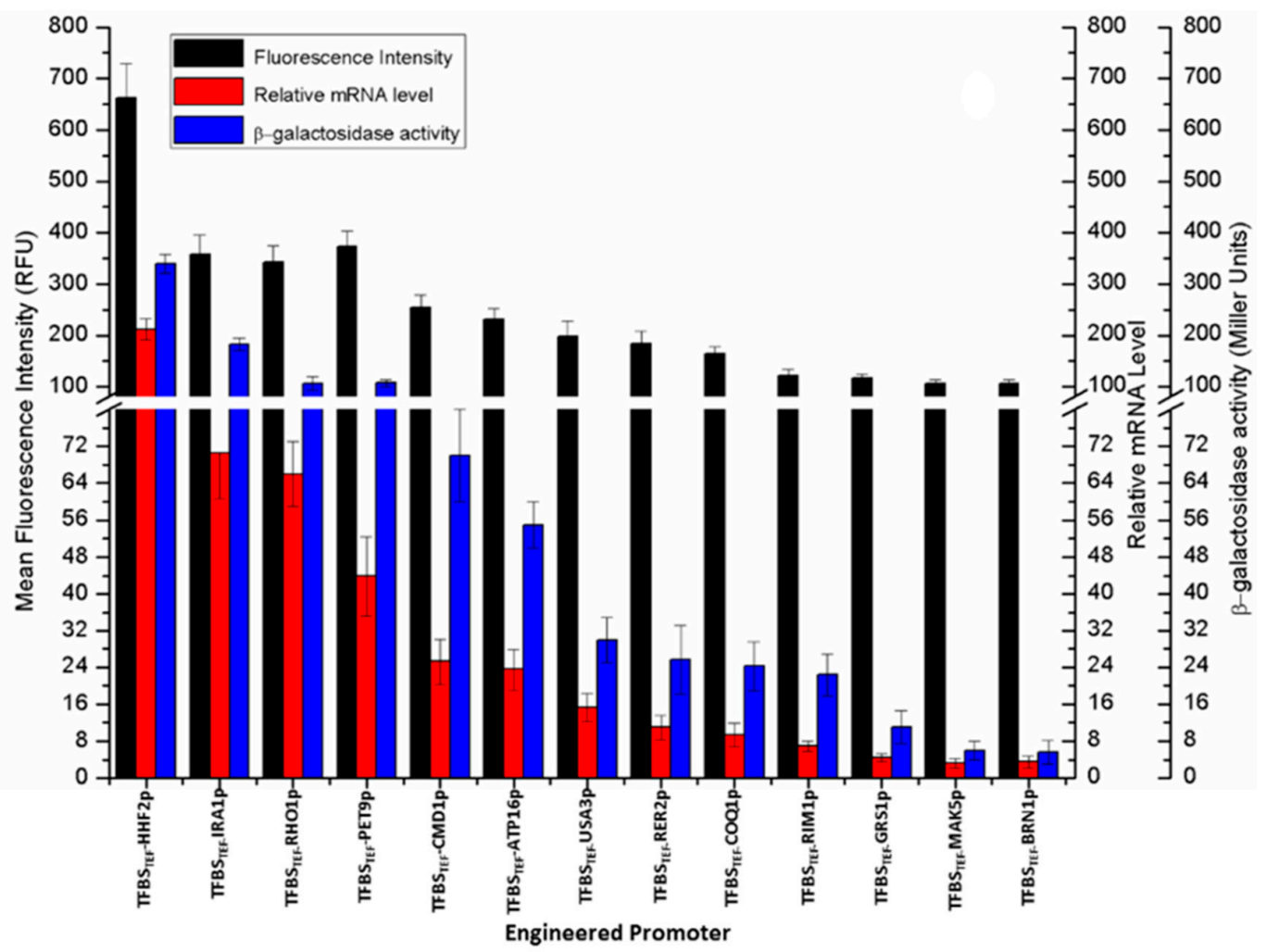

(b)

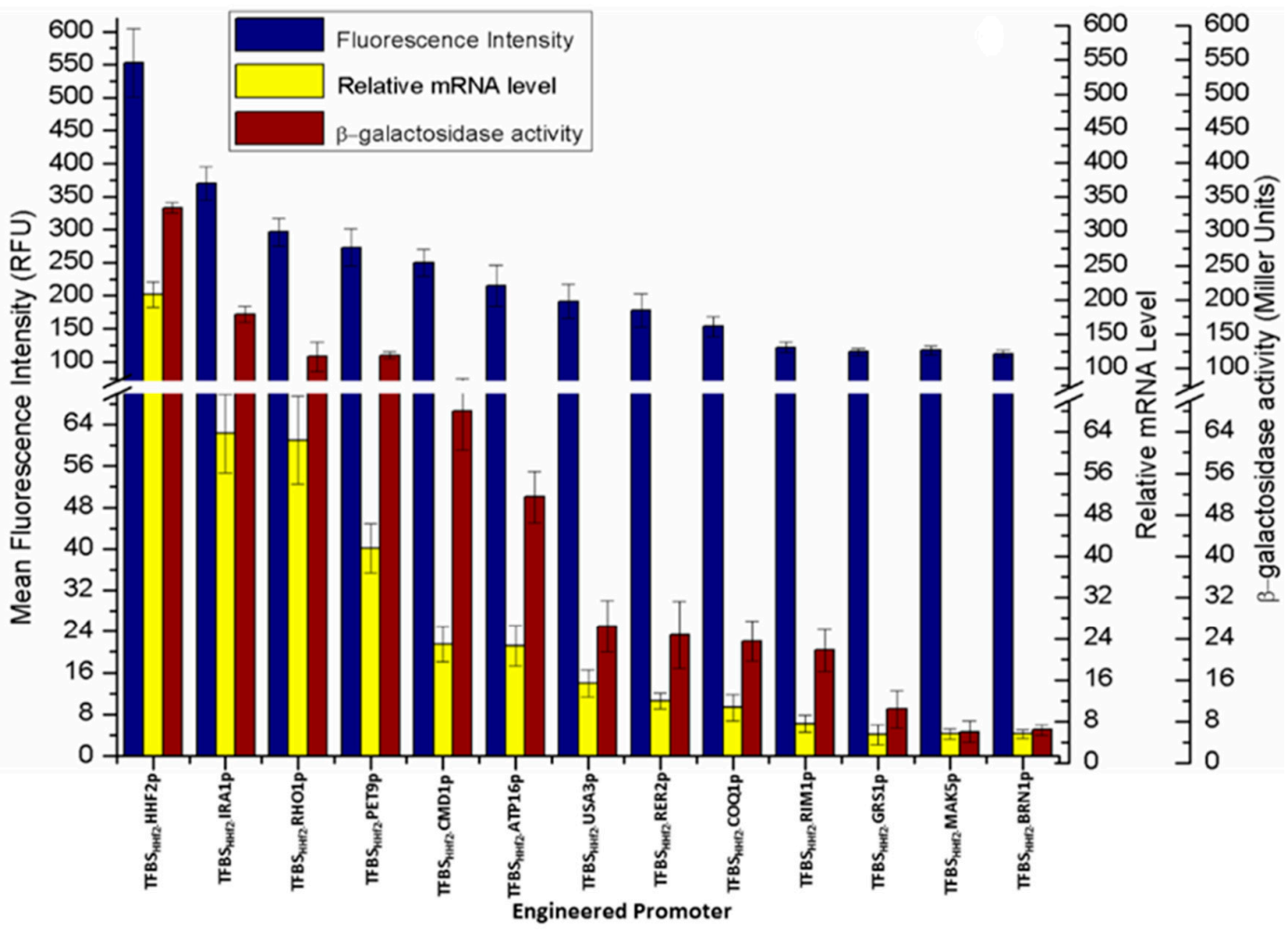

(c)

Figure 2. Cont. 


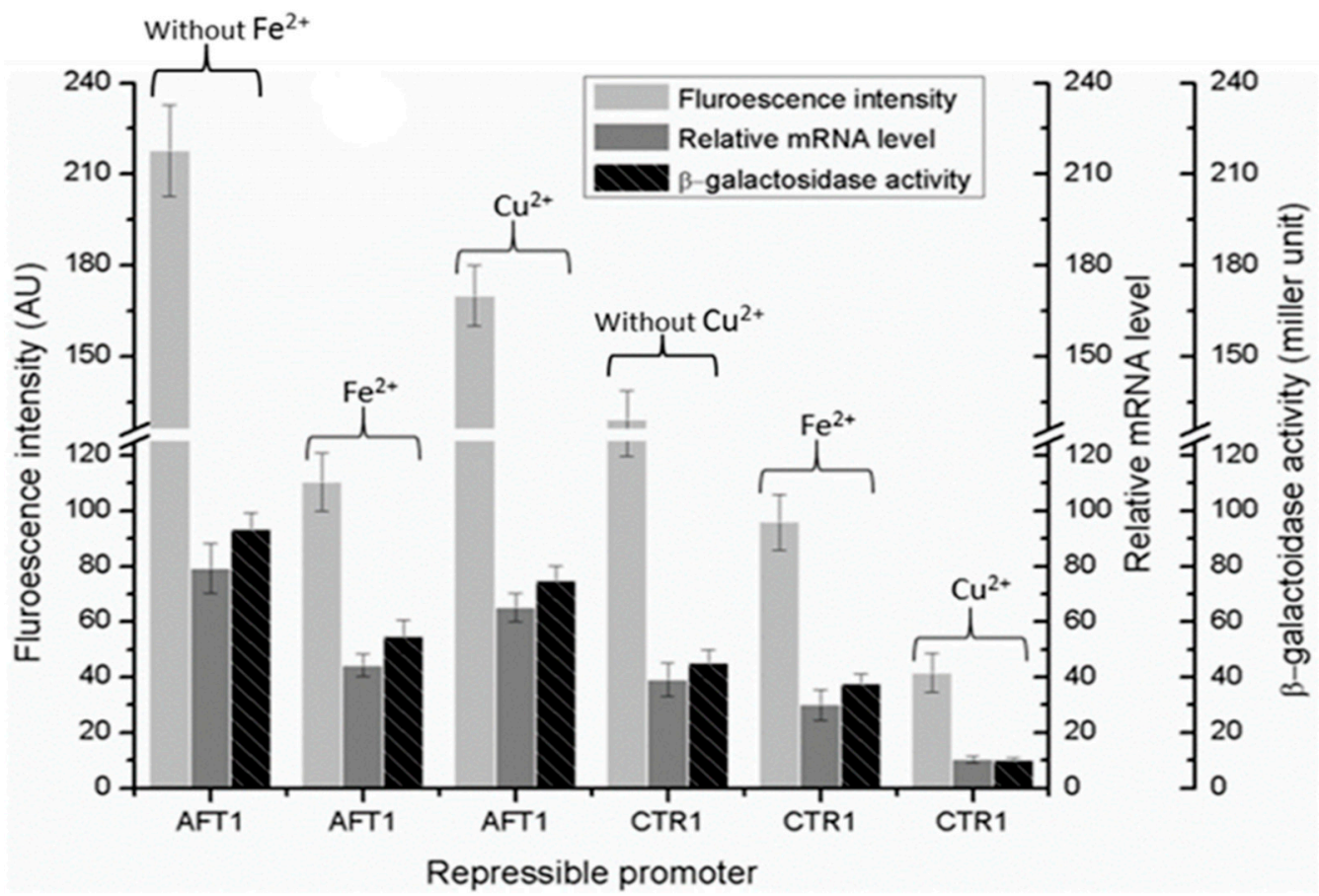

(d)

Figure 2. Tuning of the strength of yeast constitutive promoters: (a) Strategy for tuning the strength of yeast constitutive promoters transcription factor binding sites (TFBS) from strong constitutive promoters TEF1p ( -300 to $-579 \mathrm{bp}$ ) and HHF2 $p$ (-300 to $-669 \mathrm{bp})$. (b) Characterization of the strength of engineered promoters constructed by ligating the TFBS - TEF1p upstream of HHF2, IRA1p, RHO1p, PET9p, CMD1p, ATP16p, USA3p, RER2p, COQ1p, RIM1p, GRS1p, MAK5p, and BRN1p using reporter genes EGFP and $L a c Z$. (c) Characterization of the strength of engineered promoters constructed by ligating the TFBS $_{-H H F 2 p}$ upstream of HHF2 $p$, IRA1p, RHO1p, PET9p, CMD1p, ATP16p, USA3p, RER2p, COQ1p, RIM1p, GRS1p, MAK5p, and BRN1p using reporter genes EGFP and LacZ. Error bars represent the standard deviation of biological triplicate. (d) Characterization of the strength of metal ion repressible promoters. The strength of AFT1p and CTR1p was characterized using reporter genes EGFP and LacZ. Metals ion, $\mathrm{Fe}^{2+}$, and $\mathrm{Cu}^{2+}$, were tested to repress the strength of AFT1p and CTR1p promoters. Both metals ion repressed the strength of AFT1p and CTR1p to a different level. Error bars represent the standard deviation of biological triplicate.

\subsection{Characterization of Metal Ion Repressible Promoters}

Repressible promoters, a vital tool of metabolic engineering, are employed to downregulate the expression of genes competing for precursors with an engineered pathway. Methionine repressible promoter (Met3p) has been previously employed to downregulate the expression of different genes [32], but its use is not industrially viable due to its high cost and consumption by the cell for growth.

Metal ion repressible promoters are a sustainable alternative to metabolite repressible promoters due to their cheap cost and little consumption by the cell for growth. Transcription factor Aft1 induces the expression of iron regulon genes in the iron-deficient yeast cell and promotes the iron uptake by stimulating the remodeling of cellular metabolism [33]. CTR1 encodes plasma membrane protein required for high-affinity uptake of copper from the growth medium, but its transcription is strongly repressed by copper ions [34]. The repression of AFT1p and CTR1p was determined in terms of fluorescence intensity and relative mRNA level of EGFP and unit activity of $\beta$-galactosidase. The strength of AFT1p was repressed by 2-fold and 1.33-fold, respectively, using $\mathrm{Fe}^{2+}$ and $\mathrm{Cu}^{2+}$ (Figure 2d). The strength of CTR1p was repressed by 1.42-fold 3.38-fold, respectively, using $\mathrm{Fe}^{2+}$ and $\mathrm{Cu}^{2+}$ (Figure 2d). 


\subsection{Overexpression of the Squalene Synthesis Pathway in Yeast Via Engineered Promoters}

The terpenoid biosynthesis pathway of $S$. cerevisiae has been abundantly maneuvered for overproduction of heterologous isoprenoids, such as miltiradiene [35], artemisinic acid [36], $\alpha$-santalene [37], $\beta$-amyrin [38] violacein [39]. Similarly, S. cerevisiae can also be customized to overproduce the native isoprenoids, including isopentenol, farnesol, and squalene, etc. Mevalonate pathway (MVA) is an indispensable segment of the squalene biosynthesis pathway (SB pathway), leading to the production of isopentenyl diphosphate precursor of squalene [40]. HMG-CoA (HMG1) reductase catalyzes the rate-limiting step of the MVA pathway; its overexpression has been reported to enhance the production of squalene in S. cerevisiae [41]. Isopentenyl diphosphate isomerase-1 (IDI1) controls the flow of isopentenyl pyrophosphate/dimethylallyl pyrophosphate (IPP/DMAPP) to the SB pathway [38]. Farnesyl diphosphate synthase (ERG20) stands at the major intersection of the SB pathway and synthesizes the FDP by condensing isopentenyl diphosphate that is used for biosynthesis of squalene, sterols, dolichols, ubiquinone and prenylated proteins [42]. Squalene synthase (ERG9) performs the first committed reaction of the ergosterol biosynthesis pathway leading to the production of squalene through condensation of two molecules of FDP. Keeping in view the critical role of HMG-CoA reductase, isopentenyl diphosphate isomerase-1, farnesyl diphosphate synthase, and squalene synthase in the biosynthesis of squalene, the genes HMG1, IDI1, ERG20, and ERG9 of enzymes mentioned above were overexpressed using TFBS $S_{\text {TEF- }} H H F 2 p, T F B S_{\text {TEF- }} I R A 1 p$,

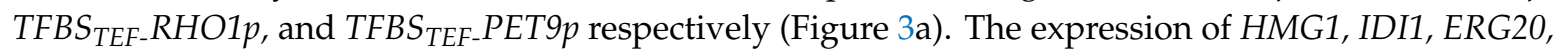
and ERG9 was enhanced by 13.67-fold, 16.33-fold, 7.24-fold, and 9.46-fold, respectively in FSE strain than WS (Figure 3b). FSE strain also produced 16.43 -fold (56.20 mg/L) higher squalene than WS (Figure 4a). The production of squalene in FSE strain was confirmed through GC-MS spectrometry by comparing the GC-MS spectra of the sample with an authentic standard of squalene and fragmentation fingerprint of squalene in the NIST library database (Figure S6a,e). The overproduction of squalene in FSE strain also caused the reduction of ethanol production in FSE strain by 4.18 fold than the WS strain (Figure 4c) and endorsed the results of the earlier study [15].

\section{Module-1}
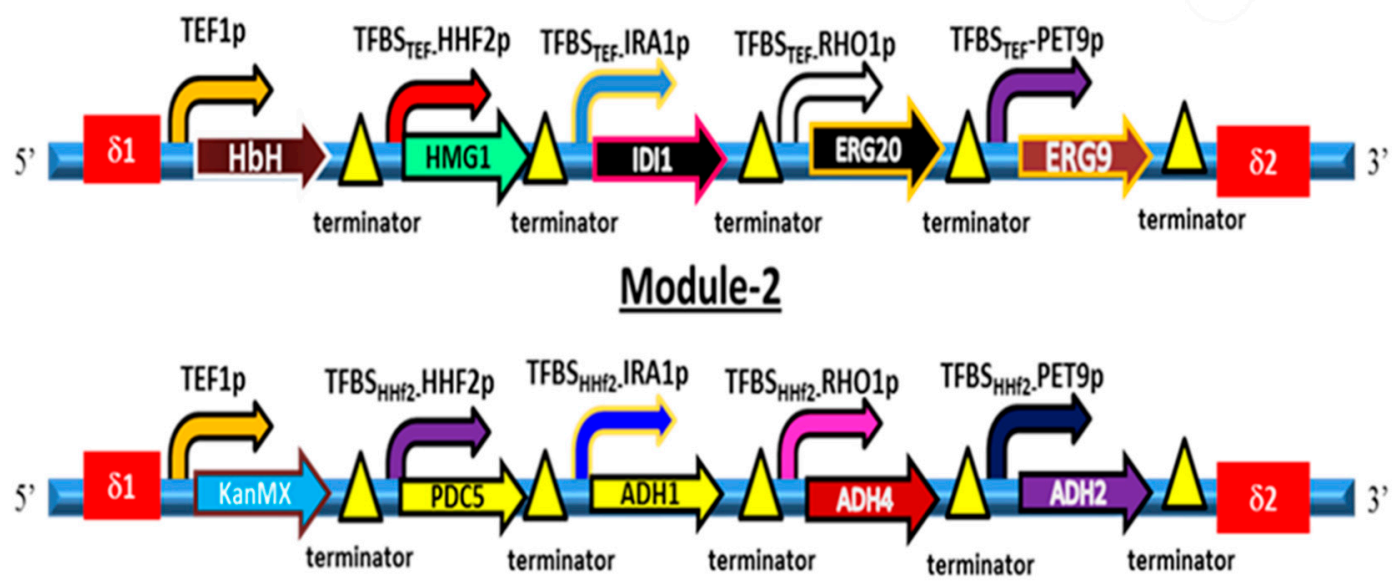

(a)

Figure 3. Cont. 


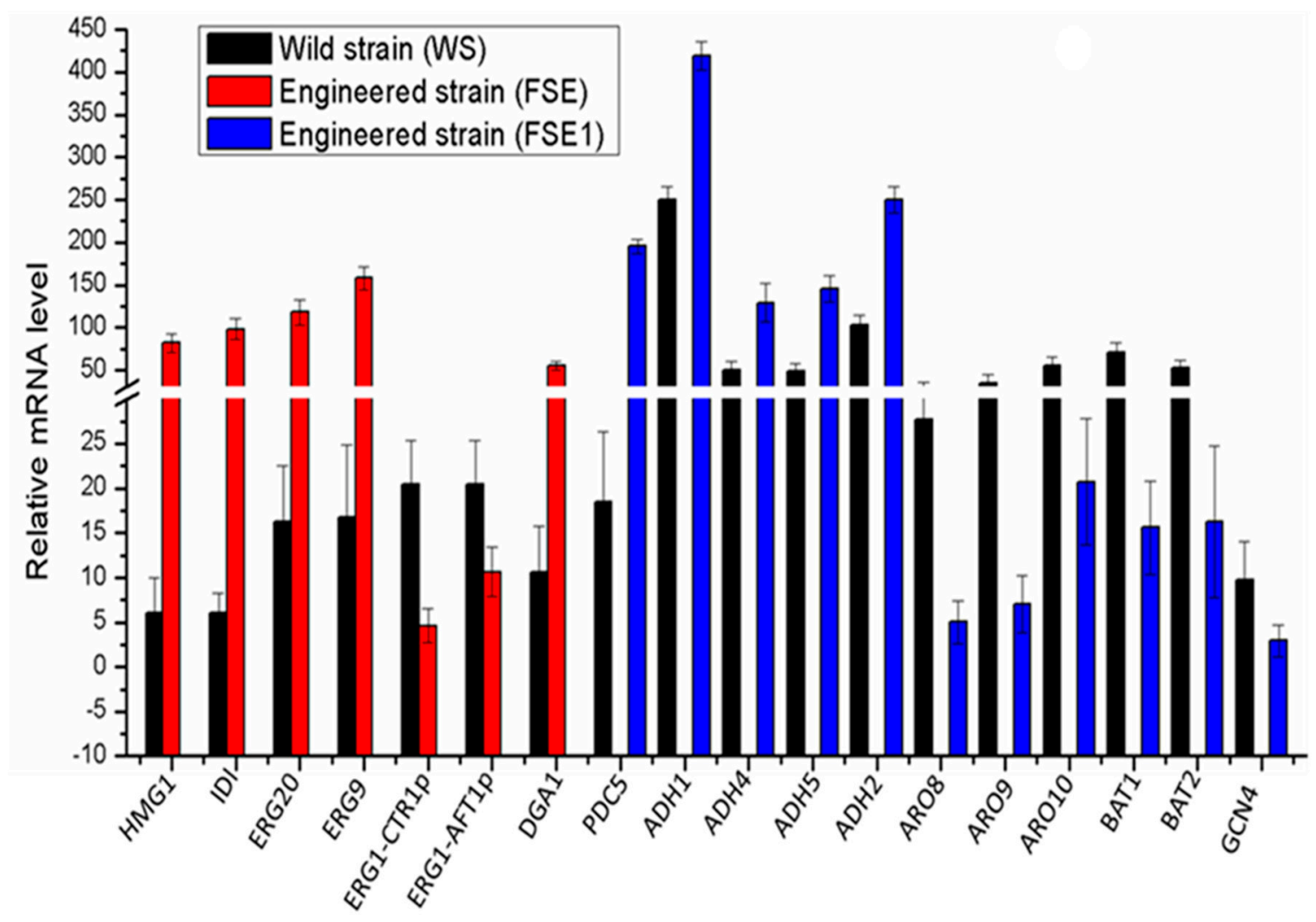

(b)

Figure 3. (a) Module-1 consists of HMG1, IDI1, ERG20 and ERG9 genes of squalene biosynthesis pathway, was transformed into Saccharomyces cerevisiae leading to the FSE strain and module-2 comprises of PDC5, $A D H 1, A D H 4, A D H 5$ and $A D H 2$ genes of ethanol production pathway was transformed into FSE strain leading to the FSE strain. Engineered promoters TFBS $S_{T E F}-H H F 2 p, T F B S_{T E F}-I R A 1 p, T F B S_{T E F}-R H O 1 p$, $T_{T F B S}$ TEF $^{-P E T 9 p}$, and TFBS $S_{H H F 2}-H H F 2 p, T F B S_{H H F 2}-I R A 1 p, T F B S_{H H F 2}-R H O 1 p, T F B S_{H H F 2}-P E T 9 p$ were employed to overexpress the genes of squalene and ethanol production pathways, respectively. Names of the terminators are given in Table S2 with their primers. (b) qRT-PCR analysis of (i) overexpressed genes of SB and EP pathways, (ii) ERG1 under repressible promoters, (iii) genes of fusel alcohol pathway: The expression level of HMG1, IDI1, ERG20 and ERG9 genes of squalene biosynthesis pathway was

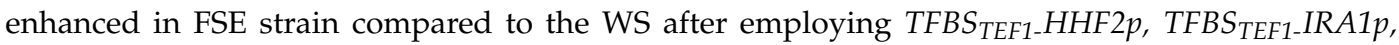
$T F B S_{T E F 1-}$ RHO1p, and TFBS $S_{T E F 1-P E T 9 p}$ promoters, respectively. The expression level of the ERG1 gene was decreased in FSE strain compared to the WS after employing AFT1p and CTR1p repressible promoters. The expression level of $P D C 5, A D H 1, A D H 4, A D H 5$, and $A D H 2$ genes was enhanced in FSE1 strain compared to the WS after employing the TFBS ${ }_{H H F 2}$ HHF2 $p, T F B S_{H H F 2}$ IRA1p, TFBS HHF2 $_{\text {RHO1p }}$,

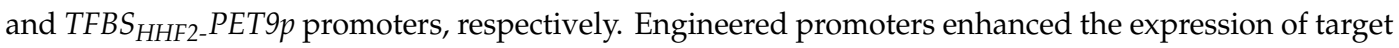
genes of each pathway, and metal ion repressible promoters downregulated the expression of ERG1 genes. The expression level of genes such as transcription factor regulator GCN4 and ARO8, ARO9, $A R O 10, B A T 1$, and BAT2 of fusel alcohol pathway in FSE1 strain compared to the wild type strain (WS) was downregulated. Error bars represent the standard deviation of biological triplicate. 


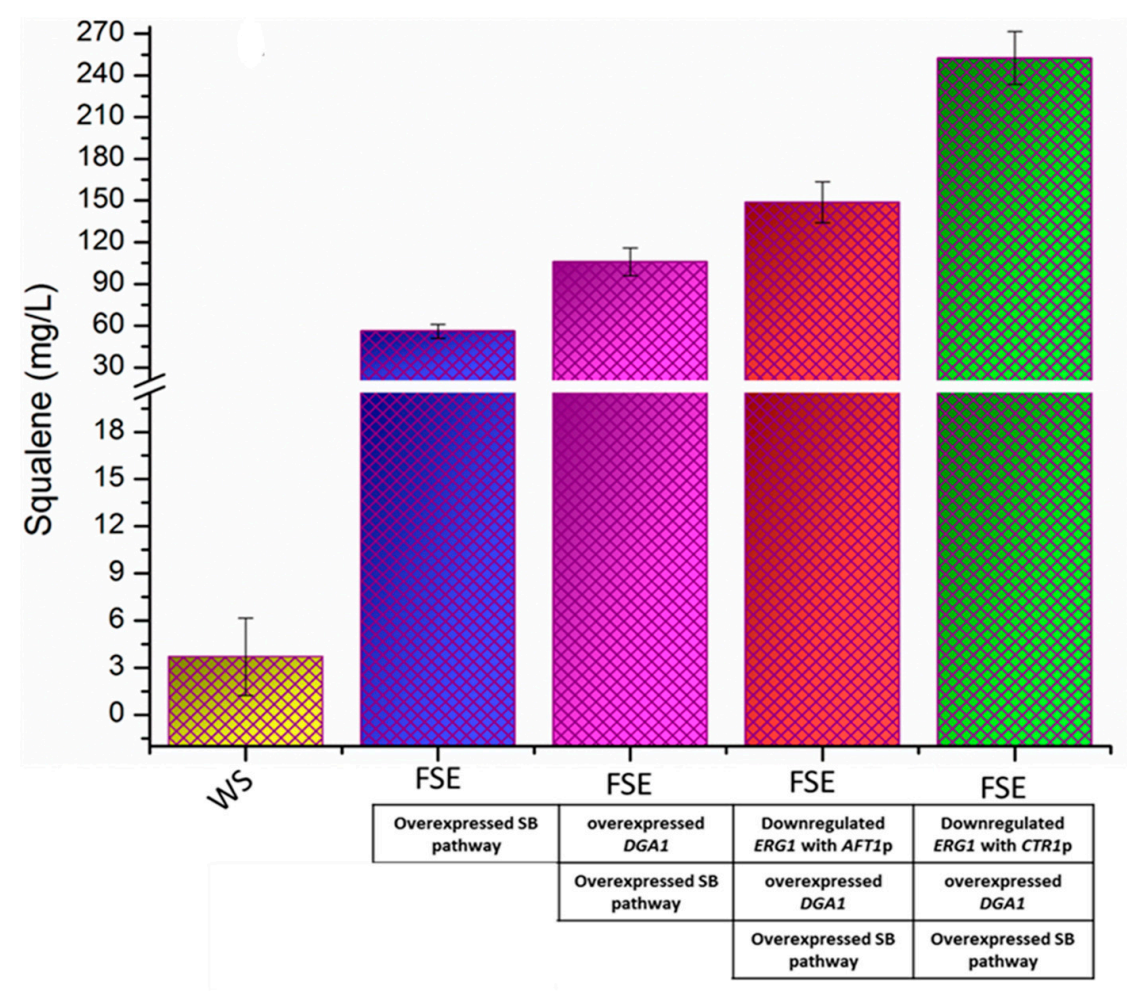

(a)

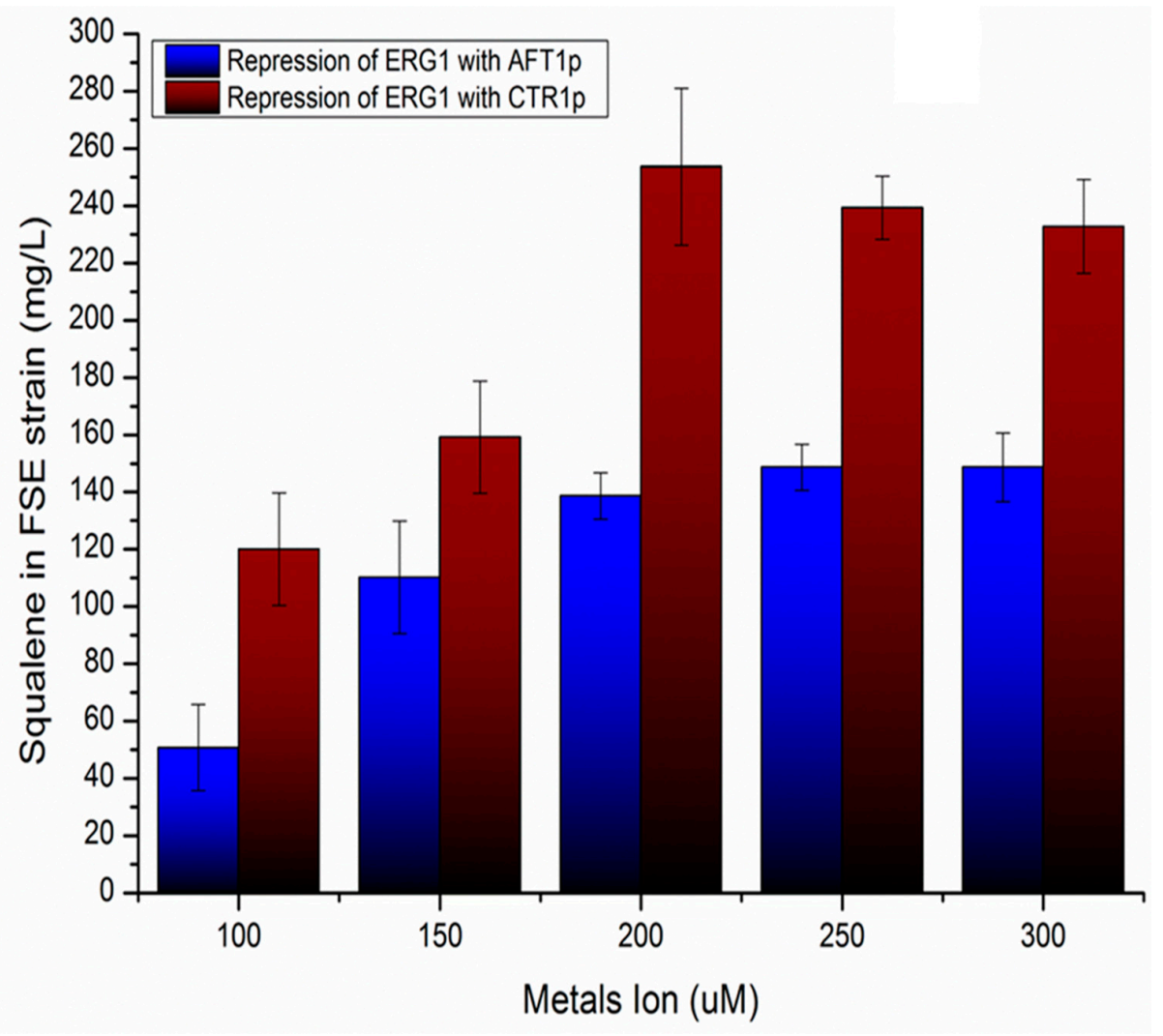

(b)

Figure 4. Cont. 


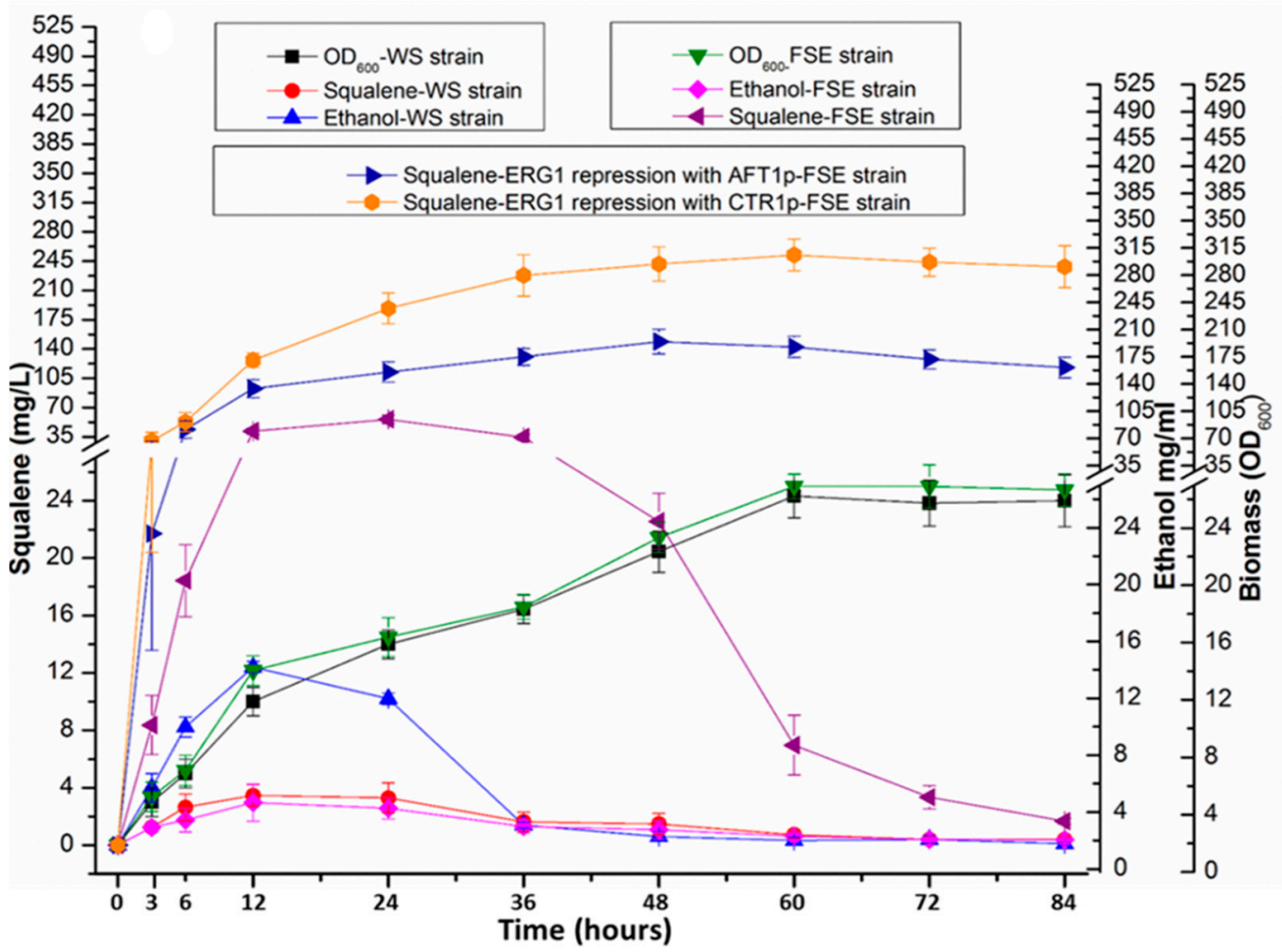

(c)

Figure 4. (a) Optimization of squalene overproduction in FSE strain. Production of squalene in FSE strain was optimized by overexpressing the DGA1 and downregulation of ERG1 using AFT1p and CTR1p repressible promoters. By overexpressing DGA1 and downregulation of ERG1 using CTR1p maximum amount of squalene was produced in FSE strain. Error bars represent the standard deviation of biological triplicate. (b) Dose optimization of metals ion for the downregulation of ERG1 to optimize the squalene production in FSE strain. Different concentrations of $\mathrm{Fe}^{2+}$ and $\mathrm{Cu}^{2+}$ including, $100 \mathrm{uM}$, $150 \mathrm{uM}, 200 \mathrm{uM}, 250 \mathrm{uM}$, and $300 \mathrm{uM}$ were tested to repress the AFT1p and CTR1p respectively. CTR1p was strongly repressed by $\mathrm{Cu}^{2+}$ at $200 \mathrm{uM}$, while $A F T 1 p$ was strongly repressed by $\mathrm{Fe}^{2+}$ at $250 \mathrm{uM}$. The expression of ERG1 was strongly downregulated using CTR1p at $200 \mathrm{uM}$ of $\mathrm{Cu}^{2+}$ compared to the AFT1p at $250 \mathrm{uM}$ of $\mathrm{Fe}^{2+}$. Error bars represent the standard deviation of biological triplicate. (c) Time course of squalene and ethanol co-production in FSE strain. Engineered FSE strain produced the maximum amount of squalene till $24 \mathrm{~h}$ of growth and started consuming it after $24 \mathrm{~h}$ of fermentation. The downregulation of ERG1 by AFT1p and CTR1p separately caused the maximum accumulation of squalene up to $48 \mathrm{~h}$ and $60 \mathrm{~h}$, respectively, in FSE strain. FSE strain producing maximum titer of squalene by repressing ERG1 with CTR1p also reduced the production of ethanol.

\subsection{Optimization of Squalene Overproduction Via Overexpression of DGA1 and Downregulation of ERG1}

The excessive cytoplasmic accumulation of olefin oils such as squalene and terpene inflict toxic effects and metabolic stress on the yeast cell $[43,44]$. However, lipid droplets in yeast can only store small quantities of olefin oil due to the tight regulation of their biogenesis [45,46]. The main function of lipid droplets is to store the hydrophobic olefins oils and relieve their toxic effect on yeast cells [47,48].

DGA1 encodes diacylglycerol O-acyltransferase, catalyzes the critical step involved in the production of triacylglycerol (TAG) and stimulation of biogenesis of lipid droplets in yeast [49]. The previous study has shown that overexpression of DGA1 enhanced the accumulation of squalene via stimulating the biogenesis of lipid droplets in yeast [44].

In this study, expression of DGA1 was enhanced by 5.25 fold using the TFBS-TEF1 IRA1 promoter, leading to the accumulation of squalene in FSE strain up to $106 \mathrm{mg} / \mathrm{L}$, a 28.61-fold higher than WS 
strain (Figures $3 \mathrm{~b}$ and $4 \mathrm{a}$ ). The biogenesis of lipid droplets in the FSE1 strain was also enhanced due to the overexpression of $D G A 1$ and visualized through staining with Nile red dye Figure S4 [50].

Squalene monooxygenase (ERG1) catalyzes the conversion of squalene into the squalene epoxide [51]. The downregulation of ERG1 up to 1.92 fold and 4.45 fold by AFT1p and CTR1p respectively (Figure 3), enhanced the production of squalene up to 42.85 -fold (148.67 $\mathrm{mg} / \mathrm{L}$ ) and 68.25 -fold $(252.51 \mathrm{mg} / \mathrm{L})$ respectively, in FSE strain higher than wild type strain (Figure $4 \mathrm{a}-\mathrm{c})$. It is evident from Figures $3 \mathrm{~b}$ and $4 \mathrm{a}-\mathrm{c}$ that CTR1p strongly repressed the expression of ERG1 compared to the AFT1p and caused the highest accumulation of squalene in FSE strain (Figure 4a-c). The addition of $\mathrm{Cu}^{2+}$ more than $200 \mathrm{uM}$ reduced the growth rate of engineered strain and also reduced the production of squalene in FSE strain (Figure 4a), therefore in subsequent observations, $200 \mathrm{uM}$ of $\mathrm{Cu}^{2+}$ was used.

To our knowledge, FSE strain produced the highest titer of the squalene in shake flask without using expensive inhibitors or repressors. The fermentation in the fed-batch fermenter can further enhance the titer of squalene by FSE strain.

\subsection{Co-Overproduction of Ethanol in S. cerevisiae}

Ethanol is a viable alternative to fossil fuel and also used in the preparation of various alcoholic beverages. Earlier it has been reported that squalene overproducing yeast self-downregulates the expression of ethanol production pathway (EP), a non-essential pathway for yeast growth and survival [15]. Later, through the literature review, it was also found that the fusel alcohol pathway is also non-essential for yeast growth and survival $[18,22]$. Therefore, ethanol and squalene production pathways were co-expressed to determine their impact on the expression and production of the fusel alcohol pathway in yeast.

Pyruvate decarboxylase (PDC5) is a key enzyme of the ethanol pathway, catalyzes the conversion of pyruvate into acetaldehyde [52]. Alcohol dehydrogenase 1 (ADH1), alcohol dehydrogenase IV $(A D H 4)$, alcohol dehydrogenase $2(A D H 2)$, and alcohol dehydrogenase 5 (ADH5) catalyze the reduction of acetaldehyde into ethanol $[53,54]$. Essential genes, (i) PDC5 (pyruvate decarboxylase 5), (ii) ADH1 (alcohol dehydrogenase 1), (iii) $A D H 4$ (alcohol dehydrogenase 4), (iv) $A D H 5$ (alcohol dehydrogenase 5) and (v) ADH2 (alcohol dehydrogenase 2) of ethanol pathway using TFBS HHF2 $_{\text {HHF2 }}$, TFBS HHF2 IRA1 $_{\text {, }}$, $T_{F B S} S_{H H F 2-R H O 1 p}$, and TFBS $S_{H H F 2-P E T 9 p}$, respectively were expressed in FSE strain leading to FSE1 strain (Figure 3a). Employment of engineered promoters successfully enhanced the expression of PDC5 (pyruvate decarboxylase 5), ADH1 (alcohol dehydrogenase 1), ADH4 (alcohol dehydrogenase 4), $A D H 5$ (alcohol dehydrogenase 5) and ADH2 (alcohol dehydrogenase 2) by 10.56-, 1.68-, 2.58-, 2.97-, and 2.44-fold, respectively in FSE1 strain than wild type strain (Figure 3b). FSE1 strain co-overexpressing ethanol and squalene pathways co-produced $40.2 \mathrm{mg} / \mathrm{mL}$ and $255.11 \mathrm{mg} / \mathrm{L}$ ethanol and squalene, respectively (Figure 5a,b).

\subsection{Yeast Co-Producing the Squalene and Ethanol Self-Downregulated the Expression of Fusel Alcohol Pathway}

Fusel alcohols are produced by yeast during fermentation and impart flavor to fermented foods and beverages [17]. Fusel alcohol are produced from catabolism of amino acids [18], including branched-chain amino acids (leucine, valine, and isoleucine), aromatic amino acids (phenylalanine, tyrosine, and tryptophan), and sulfur-containing amino acid (methionine) [18].

Yeast tightly regulates the expression of anabolic and catabolic pathways through multiple regulatory networks [55]. The yeast SPT10 gene encodes a putative histone acetyltransferase (HAT) is implicated as a global transcription regulator acting through basal promoters [56]. In another study, the secretion of the SW14 protein was enhanced through global level tuning of gene expression by engineering the expression of TF. Earlier it has been reported that squalene overproducing yeast self-downregulated the ethanol production pathway through cryptic regulatory pathway [15]. Herein, it was aimed to evaluate the effect of squalene and ethanol co-overproduction on the expression of the fusel pathway of yeast. 


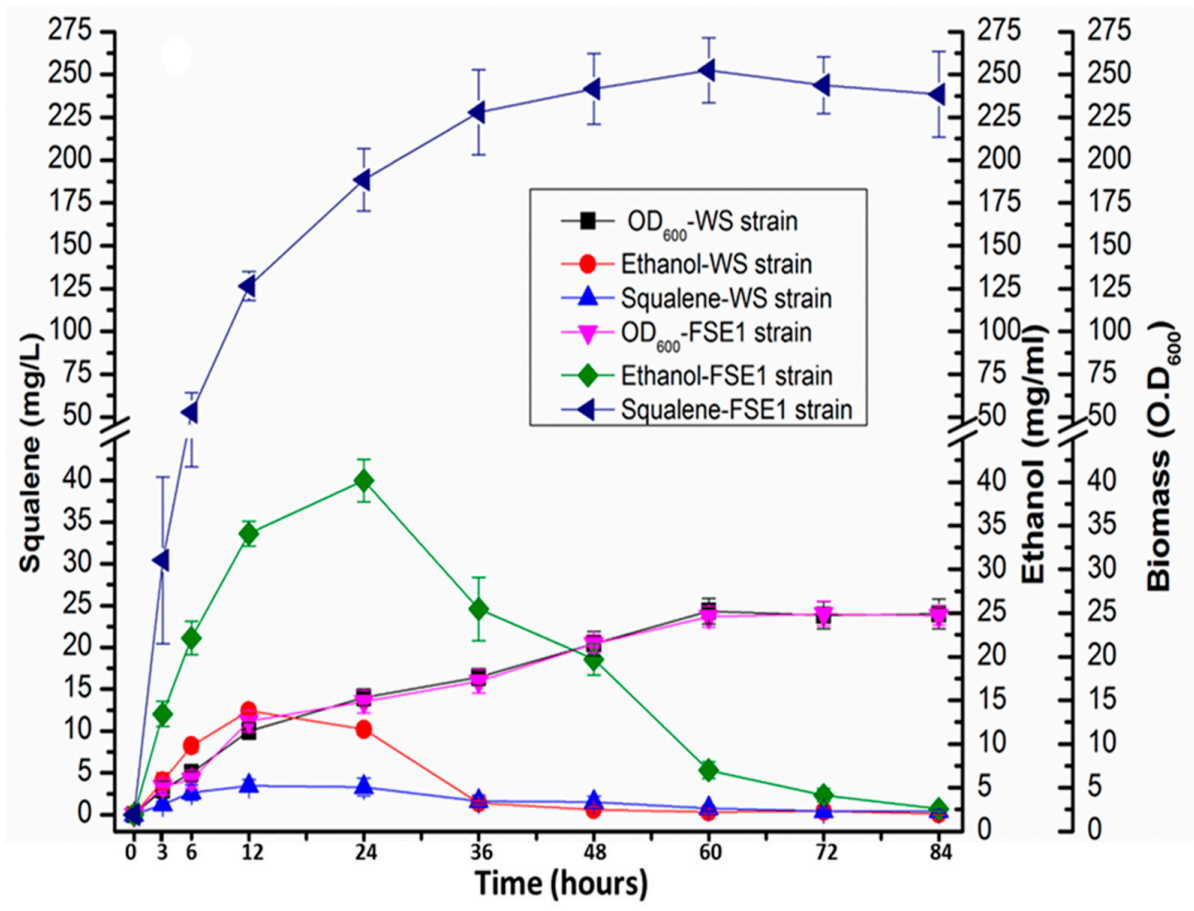

(a)

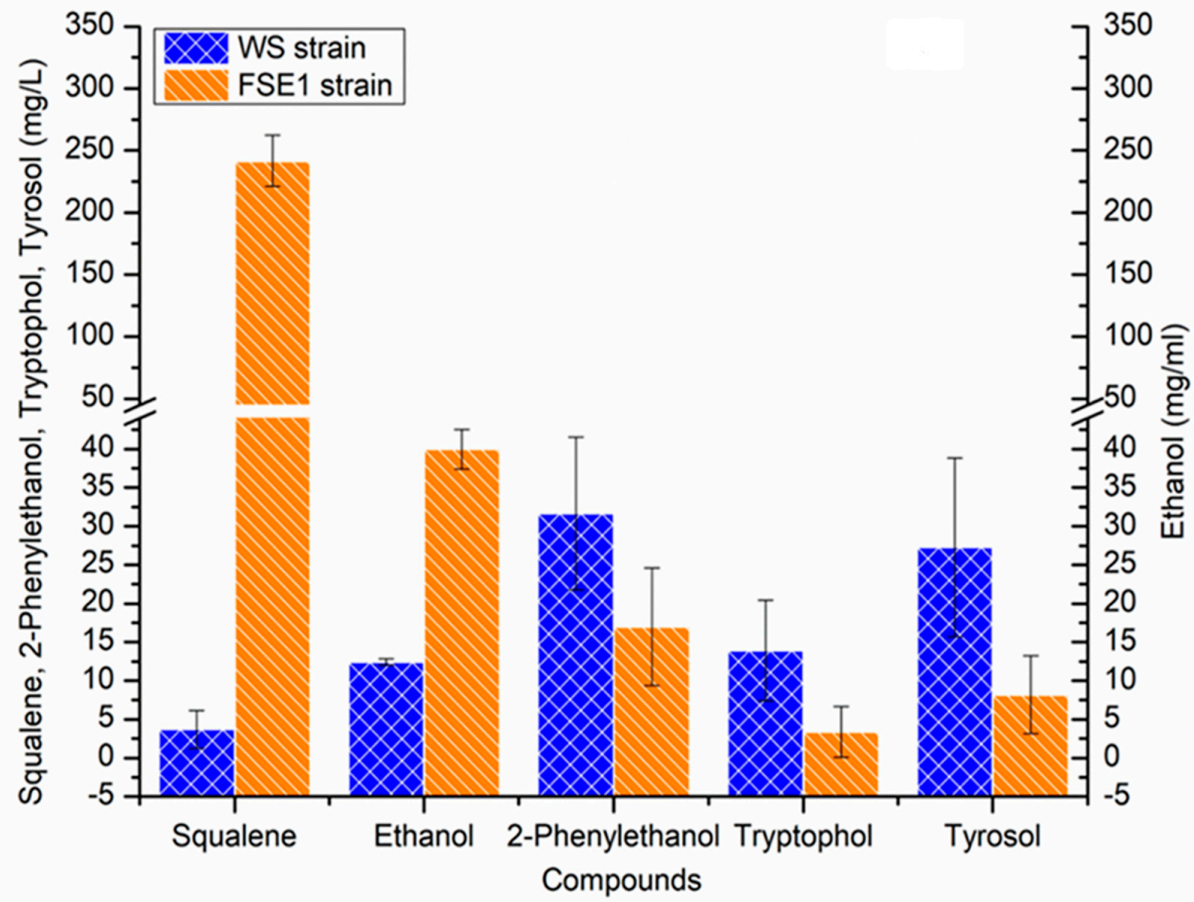

(b)

Figure 5. (a) Time course of squalene and ethanol co-production by FSE1 strain: Engineered FSE1 strain after co-expressing the squalene and ethanol pathways produced maximum titer of ethanol and squalene till 24th- and 60th hours respectively, of growth (b) Squalene and ethanol co-production in FSE1 strain caused the reduction of production of fusel alcohols including, 2-Phenylethanol, tyrosol, tryptophol compared to the WS. However, it also reduced the production of fusel alcohol including, 2-Phenylethanol, tryptophol, and tyrosol. It shows the self-diversion of metabolic flux by FSE1 in response to metabolic burden. 
It was found that squalene and ethanol co-overproducing FSE1 strain self-downregulated the expression of ARO8 (aromatic/aminoadipate aminotransferase 1), ARO9 (aromatic amino acid aminotransferase 2), ARO10 (transaminated amino acid decarboxylase), BAT1 (branched-chain amino-acid aminotransferase, mitochondria), and BAT2 (branched-chain amino acid aminotransferase, cytosol) genes of fusel alcohol pathway by 5.48-fold, 5.05-fold, 2.67-fold, 4.54-fold, and 3.26-fold respectively, collectively $73.9 \%$, than WS strain (Figure 3). Although fusel alcohol are comprised of catabolic products of branched-chain amino acids and aromatic amino acids, the effect of squalene and ethanol, co-overproduction was determined on the catabolism of aromatic amino acids, including, 2-phenylethanol (phenylalanine), tyrosol (tyrosine), tryptophol (tryptophan). FSE1 strain produced 2-phenylethanol, tyrosol, tryptophol by 1.87-fold, 4.12-fold and 3.33-fold respectively, less than WS strain (Figure $5 \mathrm{~b}$ and Figure $\mathrm{S} 6 \mathrm{~b}-\mathrm{d}, \mathrm{f}-\mathrm{h}$ ). The expression of positive transcriptional factor regulator GCN4 was also downregulated by 2.24-fold in the FSE1 strain (Figure 3). However, the effect of squalene overproduction was also determined on the fusel alcohol pathway, but no perturbation was observed. However, the production of ethanol was reduced in FSE strain by 4.18 fold than WS strain (Figure 4c), which was later improved in FSE1 strain by overexpressing the ethanol pathway (Figure 5a,b).

This indicates the presence of a cryptic global regulatory pathway operating through different regulators to redirect the metabolic flux to engineered pathways. We surmise that perhaps cryptic global regulatory pathway signaled the downregulation of GCN4 and prevented the loss of carbon skeleton in the cell medium and directed the redirection of metabolic flux toward the engineered pathway. General amino acid control protein (GCN4), generally derepress amino acid biosynthesis pathways during starvation of amino acids and also plays a critical role in controlling the spatial organization of yeast genome $[57,58]$. GCN4 positively regulates the transcription of target genes via binding at 5'-TGA[CG]TCA-3' sequence in the promoters [57].

To our knowledge, this is the first report on the highest co-production of squalene and ethanol in yeast and demonstrating the self-diversion of metabolic flux from the fusel alcohol pathway toward engineered pathways.

\section{Materials and Methods}

\subsection{Strains, Media, and Cells Cultivation}

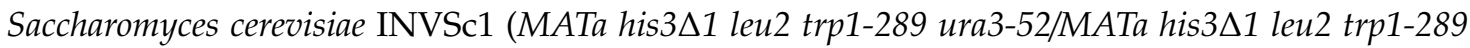
ura3-52) (Invitrogen, Carlsbad, CA) was manipulated to overexpress the squalene biosynthesis (SB) pathway and ethanol production (EP) pathways for squalene and ethanol co-production. Positive transformants harboring SB and EP pathways were selected on YPD agar plates (glucose $20 \mathrm{~g} / \mathrm{L}$, tryptone $20 \mathrm{~g} / \mathrm{L}$, yeast extract $10 \mathrm{~g} / \mathrm{L}$, agar $17 \mathrm{~g} / \mathrm{L}$ ) containing $500 \mathrm{mg} / \mathrm{L}$ hygromycin B (Roche, Indianapolis, IN) and $300 \mathrm{mg} / \mathrm{L}$ geneticin respectively. Positive transformants harboring AFT1p and CTR1p modules were selected on histidine negative nutrient agar plates, while positive transformants carrying GCN4 module were selected on tryptophan negative nutrient agar plate. The optical density $\left(\mathrm{OD}_{600}\right)$ of fermenting cultures was measured using a spectrophotometer (model U-2900, HITACHI, Chiyoda, Tokyo).

\subsection{Tuning the Strength of Promoters}

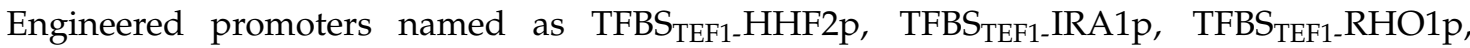

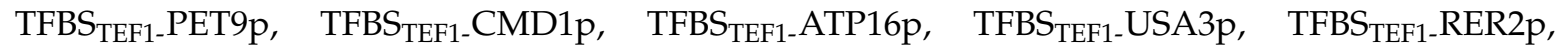
TFBS $_{\text {TEF1-COQ1p, TFBS }}$ TEF1-RIM1p, TFBS TEF1-GRS1p, TFBS $_{\text {TEF1-MAK5p, TFBS }}$ TEF1-BRN1p and

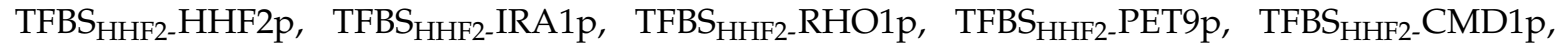

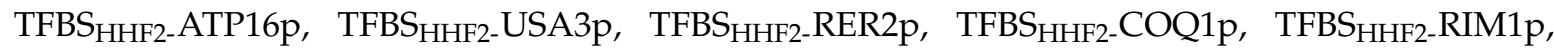

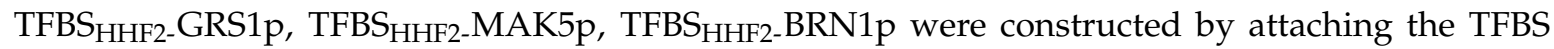
of TEF1p ( -300 to $-579 \mathrm{bp}$ ) and HHF2p (-300 to $-669 \mathrm{bp}$ ) promoters, respectively, upstream of HHF2p, 
IRA1p, RHO1p, PET9p, CMD1p, ATP16p, USA3p, RER2p, COQ1p, RIM1p, GRS1p, MAK5p, and BRN1p yeast constitutive promoters. All sequences of the promoters were amplified from the genomic DNA of S. cerevisiae. The reporter genes of EGFP and LacZ used to measure the strength of engineered promoters were amplified from previously constructed plasmid pET-28a (+)-pykA-egfp and genomic DNA of E. coli, respectively.

The primers for amplification of transcriptional factor binding sites, native promoters, and reporter genes were designed as that the $39 \mathrm{bp}$ at $5^{\prime}$ end of each transcriptional binding site overlaps with $39 \mathrm{bp}$ at $3^{\prime}$ end of the BamHI digested plasmid pRS41H, whereas $39 \mathrm{bp}$ at $3^{\prime}$ end of each transcriptional binding site overlaps with $39 \mathrm{bp}$ at $5^{\prime}$ end of each native promoter (e.g., BRN1p) and $39 \mathrm{bp}$ at $3^{\prime}$ end of each native promoter overlaps with $39 \mathrm{bp}$ at $5^{\prime}$ end of each reporter gene, and $39 \mathrm{bp}$ at $3^{\prime}$ of each reporter gene overlaps with $5^{\prime}$ end of the BamHI digested plasmid pRS41H. The primers sequences used to amplify the transcription factor binding sites, promoters, and reporter genes are given in Table S1a. In this study, the DNA assembler method was used for the in-vivo assembly of fragments of expression cassettes in S. cerevisiae [59]. This method requires the simple DNA preparation and one-step yeast transformation [59]. The workflow of the characterization of the strength of the promoters is given in Figure S1. The difference between the means was considered significant at $p<0.05$, and it was measured using the ANOVA test.

\subsection{Characterization of Metal Ion Repressible Promoters}

The metal ion repressible promoters AFT1p and CTR1p were characterized using reporter genes of EGFP and LacZ. The primers for metal ion repressible promoters and reporter genes were designed as that the $39 \mathrm{bp}$ at $5^{\prime}$ end of each repressible promoter overlaps with $39 \mathrm{bp}$ at $3^{\prime}$ end of BamHI digested pRS41H plasmid, whereas $39 \mathrm{bp}$ at $3^{\prime}$ end of the repressible promoter overlaps with $39 \mathrm{bp}$ at $5^{\prime}$ end of each reporter gene and $39 \mathrm{bp}$ at $3^{\prime}$ of each reporter gene overlaps with $5^{\prime}$ end of BamHI digested pRS41H plasmid. Oligonucleotides sequences used for amplification of transcription factor binding sites, promoters, and reporter genes are given in Table S1b. In this study, the DNA assembler method was used for the in-vivo assembly of fragments of expression cassettes in S. cerevisiae [59]. This method requires the simple DNA preparation and one-step yeast transformation [59]. The workflow of the characterization of the strength of the promoters is given in Figure S1.

\subsection{Characterization of the Strength of Engineered Promoters and Metal Ion Repressible Promoters}

The strength of the engineered and metal ion repressible promoters was reckoned in terms of fluorescence intensity and relative mRNA level of EGFP as well as via enzymatic activity of $\beta$-galactosidase. Fluorescence intensity of the EGFP downstream of each promoter was reckoned using cytation-3 microplate reader (BioTek, Winooski, VT). For microplate reader analysis, single colony of each promoter harboring strain was inoculated in $10 \mathrm{~mL}$ test tube flask containing $5 \mathrm{~mL}$ YPD broth and incubated at $30^{\circ} \mathrm{C}$ in shake rotary revolving at $170 \mathrm{rpm}$ for overnight period, and then $1 \%$ inoculum of each strain was further grown in $20 \mathrm{~mL}$ Erlenmeyer flask containing $10 \mathrm{~mL}$ YPD broth and incubated at $30{ }^{\circ} \mathrm{C}$ in shake rotary revolution $170 \mathrm{rpm}$ for $48 \mathrm{~h}$. Afterward, $1 \mathrm{~mL}$ culture of each strain was harvested, then centrifuged at $1000 \mathrm{~g}$ at $4{ }^{\circ} \mathrm{C}$ for 5 min and washed twice with ice-cold PBS buffer, and finally, the fluorescence intensity of EGFP was measured by using a microplate reader set at excitation wavelength $488 \mathrm{~nm}$, and emission wavelength $509 \mathrm{~nm}$. In addition to this, the strength of each promoter was also characterized by estimating the enzymatic activity of $\beta$-galactosidase, and for this purpose, the single colony of each promoter harboring strain was grown in $10 \mathrm{~mL}$ test tube containing $5 \mathrm{~mL}$ YPD broth and incubated at $30^{\circ} \mathrm{C}$ in shake rotary revolving at $170 \mathrm{rpm}$ for overnight period, and then $1 \%$ inoculum of each strain was further grown in $20 \mathrm{~mL}$ Erlenmeyer flask containing $10 \mathrm{~mL}$ YPD broth and incubated at $30{ }^{\circ} \mathrm{C}$ in shake rotary revolution $170 \mathrm{rpm}$ for $48 \mathrm{~h}$. After that, $1 \mathrm{~mL}$ culture of each strain was centrifuged at 12,000 rpm for $1 \mathrm{~min}$, washed twice in $1 \mathrm{~mL}$ Z-buffer, and subsequently, the $\beta$-galactosidase activity was determined by using the Miller protocol. 
The strength of AFT1p and CTR1p repressible promoters was also determined in terms of fluorescence intensity and relative mRNA level of EGFP and $\beta$-galactosidase activity. For this purpose, each strain was grown by using the above-mentioned growth protocols, and samples were also prepared by following the procedures above. However, in addition to this, the repressible promoters harboring strains were grown in SD histidine negative medium containing $200 \mathrm{uM} \mathrm{FeSO}_{4}$ and $200 \mathrm{uM}$ $\mathrm{CuSO}_{4}$. AFT1p and CTR1p repressible promoters were mainly repressed by $\mathrm{Fe}^{+2}$ and $\mathrm{Cu}^{+2}$ ions, respectively, but were also weakly repressed by their alternate metal ions.

\subsection{Yeast Engineering with Squalene and Ethanol Biosynthesis Pathways}

Firstly, module-1 consisted of HMG1 (hydroxymethylglutaryl CoA reductase), IDI1 (isopentenyl diphosphate isomerase), ERG20 (farnesyl diphosphate synthase) and ERG9 (squalene synthase) vital genes of squalene biosynthesis pathway downstream of TFBS $S_{T E F-} H H F 2 p, T F B S_{T E F-I R A 1 p}$,

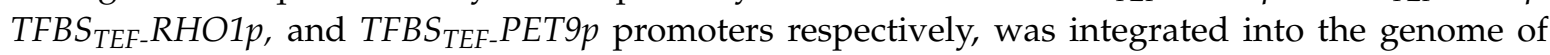
S. cerevisiae using delta site sequences (Figure 1). Secondly, module-2 comprised of PDC5 (pyruvate decarboxylase 5), ADH1 (alcohol dehydrogenase 1), ADH4 (alcohol dehydrogenase 4), ADH5 (alcohol dehydrogenase 5) and $A D H 2$ (alcohol dehydrogenase 2) vital genes of ethanol production pathway

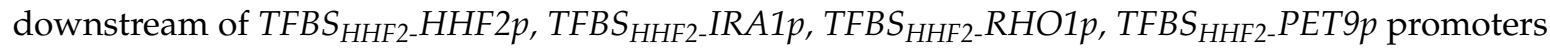
respectively, was integrated into the genome of $S$. cerevisiae using delta site sequences (Figure 1).

The $300 \mathrm{ng}$ of each expression cassette was used for the integration of module- 1 and module- 2 in the genomic DNA of S. cerevisiae (Figure 1). However, the module-1 was integrated into the genomic DNA of $S$. cerevisiae via delta sites, and they were amplified from chromosome 10 of $S$. cerevisiae. The expression cassettes of module- 2 were also integrated at the delta site in the genome of yeast. The engineered strain containing module- 1 and module- 2 was selected on the YPD agar plates containing hygromycin and geneticin (G418), respectively. In this study, the DNA assembler method was used for the in-vivo assembly of fragments of expression cassettes in S. cerevisiae [59]. This method requires the simple DNA preparation and one-step yeast transformation [59].

The primers for construction of expression cassettes of each module were designed as that the $39 \mathrm{bp}$ at $5^{\prime}$ end of the first expression cassette overlaps with $39 \mathrm{bp}$ at $3^{\prime}$ end of the delta site whereas $39 \mathrm{bp}$ at $3^{\prime}$ end of the first expression cassette overlaps with $39 \mathrm{bp}$ at $5^{\prime}$ end of the second expression cassette and so on. The primers used for amplification of delta sites, functional genes, and promoters are given in Table S2.

\subsection{Overexpression of the DGA1 in Engineered Strain}

DGA1 was overexpressed to enhance the squalene accumulation capacity of engineered strain. The primers used for the amplification of DNA fragments of the DGA1 module were designed according to the procedure mentioned in Section 2.6. The design and primers of the DGA1 module are given in Figure S2 and Table S5, respectively.

\subsection{Downregulation of ERG1 Using Metal Ion Repressible Promoters}

The metal ion repressible promoters such as AFT1p and CTR1p were employed to replace the native promoter of the ERG1 gene (squalene monooxygenase) and downregulate its expression to optimize the production of squalene in FSE strain. The native promoter of the ERG1 gene was replaced with AFT1p and CTR1p promoters through the homologous recombination pathway responsible for DSB in yeast $[60,61]$. The design of the modules used to replace ERG1p with AFT1p and CTR1 is given in Figure S3. Primers used to amplify the DNA fragments of both modules are given in Table S4. The repression potential of each metal ion repressible promoter was measured at different metal ion concentrations such as 100, 150, 200, 250, and $300 \mathrm{uM}$ of $\mathrm{FeSO}_{4}$ and $\mathrm{CuSO}_{4}$ in YPD media. All experiments were performed in biological triplicate. 


\subsection{Total RNA Extraction and qRT-PCR Analysis}

For extraction of total RNA, a single colony of engineered strain FSE and promoters harboring strains were separately inoculated in $100 \mathrm{~mL}$ Erlenmeyer flask containing $25 \mathrm{~mL}$ YPD broth and incubated at $30^{\circ} \mathrm{C}$ in shake rotary revolving at $170 \mathrm{rpm}$ for an overnight period. Subsequently, $1 \%$ culture of the overnight grown strains was separately inoculated in $100 \mathrm{~mL}$ Erlenmeyer flask containing $25 \mathrm{~mL}$ YPD broth and incubated at $30^{\circ} \mathrm{C}$ in shake rotary revolving at $170 \mathrm{rpm}$ for $48 \mathrm{~h}$. Yeast RNA Extraction Kit (OMEGA, Doraville, GA) was used for the extraction of total RNA from each sample. DNA contamination from RNA samples was excluded by adding $90 \mu \mathrm{L}$ DNase I incubation buffer plus $10 \mu \mathrm{L}$ DNase I into the RNA containing reaction tubes, afterward the reaction tubes were stored at $15^{\circ} \mathrm{C}$ for $15 \mathrm{~min}$.

The concentration of total RNA in each sample was reckoned with Nanodrop ND-1000 spectrophotometer (Thermo Scientific, Waltham, MA, USA), and the cDNA template was synthesized from one thousand nano-gram of total RNA using Transcriptor First Strand cDNA Synthesis Kit (Roche, Basel, Switzerland). Real-time qPCR reactions were performed on the LightCycler 480 real-time System (Roche, Basel, Switzerland), and reaction conditions were set as recommended by the SYBR Premix Ex Taq ${ }^{\mathrm{TM}}$ manual (Takara Biomedical Technology Co., Ltd. Beijing, China). Relative quant of each gene was determined using housekeeping gene $A C T 1$ as a reference gene, and data were analyzed with Light Cycler Software (v.1.5). All assays were performed in triplicate, and reactions without reverse transcriptase were used as a negative control. The primers for qRT-PCR analysis were designed using Beacon Designer ${ }^{\mathrm{TM}}$ Free Edition software (PREMIER Biosoft, San Francisco, CA, USA), and their sequences are tabulated in Table S3.

\subsection{Nile Red Staining of Lipid Droplets in Engineered Strain}

Nile red staining is a reliable method to monitor the neutral lipid contents of living microorganisms such as yeast and microalgae. The enhanced biogenesis of lipid droplets due to the overexpression of $D G A 1$ and subsequent accumulation of squalene in engineered strain was monitored by staining them with Nile red dye. The protocol of staining of lipid droplets with Nile red staining was used as given elsewhere in the literature [62].

\subsection{Extraction, Quantification and GC-MS Analysis of Squalene and Fusel Alcohols}

For extraction of squalene and fusel alcohols single colony of FSE, FSE1 and WS strains were separately inoculated in a $10 \mathrm{~mL}$ test tube containing $5 \mathrm{~mL}$ YPD broth and incubated at $30{ }^{\circ} \mathrm{C}$ in shake rotary revolving at $170 \mathrm{rpm}$ for an overnight period. Afterward, $1 \%$ culture of the overnight grown strains was separately inoculated in $50 \mathrm{~mL}$ Erlenmeyer flask containing $20 \mathrm{~mL}$ YPD broth and incubated at $30^{\circ} \mathrm{C}$ in shake rotary revolving at $170 \mathrm{rpm}$ for $48 \mathrm{~h}$. Later, for extraction of squalene $5 \mathrm{~mL}$ cell culture of FSE, FSE1 and WS strains were centrifuged at $900 \mathrm{~g}$ for $1 \mathrm{~min}$, and supernatant of FSE1 strain and WS was used for extraction of fusel alcohol including, 2-Phenylethanol, tyrosol, tryptophol, discarded. Afterward, $10 \mathrm{~mL}$ chloroform and $20 \mathrm{ul}$ zirconium oxide beads $(0.5 \mathrm{~mm})$ were added in the cell pellets of FSE, FSE1, and WS strains, and subsequently, each cell pellet was lyzed using bullet blender, (Next Advance, Inc. Troy, NY, USA). The lyzed cells were centrifuged at $3500 \mathrm{~g}$ for $1 \mathrm{~min}$, and the supernatant was concentrated up to $1 \mathrm{~mL}$ through evaporating rotary.

The production of squalene and fusel alcohol, e.g., 2-phenylethanol, tyrosol, tryptophol in FSE, and WS strains was determined using GCMS-ISQ trace 1300 (Thermo Fisher Scientific, Waltham, MA, USA) and TG-5MS column (Thermo Fisher Scientific, Waltham, MA, USA). The GC-MS was operated by programing it as, after injection of sample, the oven temperature was maintained at $80{ }^{\circ} \mathrm{C}$ for $1 \mathrm{~min}$, then ramped to $280{ }^{\circ} \mathrm{C}$ at the rate of $20^{\circ} \mathrm{C} / \mathrm{min}$ and held at $280{ }^{\circ} \mathrm{C}$ for $15 \mathrm{~min}$. Afterward, the temperature was further ramped to $300{ }^{\circ} \mathrm{C}$ at a rate of $20^{\circ} \mathrm{C} / \mathrm{min}$ and sustained at $300{ }^{\circ} \mathrm{C}$ for $15 \mathrm{~min}$. The peak of squalene and fusel alcohol, e.g., 2-phenylethanol, tyrosol, tryptophol in each sample were identified by comparing the GC-MS spectra of each sample with the authentic standard 
of squalene and fusel alcohol, e.g., 2-phenylethanol, tyrosol, tryptophol (Sigma-Aldrich). Furthermore, the fragmentation pattern of squalene and fusel alcohol, e.g., 2-phenylethanol, tyrosol, tryptophol in each sample, was also matched with fragmentation pattern of squalene and fusel alcohol, e.g., 2-phenylethanol, tyrosol, tryptophol in NIST library database. The production of squalene and fusel alcohol, e.g., 2-phenylethanol, tyrosol, tryptophol in FSE, and WS strains, was reckoned by constructing the standard curves of authentic standards of compounds above. All experiments were performed in triplicate.

\subsection{Quantification of Ethanol}

The production of ethanol in FSE, FSE1, and WS strains was determined by separately growing the single colony of each strain in $10 \mathrm{~mL}$ Erlenmeyer flask containing $5 \mathrm{~mL}$ YPD broth and incubated at $30{ }^{\circ} \mathrm{C}$ in shake rotary revolving at $170 \mathrm{rpm}$ for an overnight period. Subsequently, $1 \%$ inoculum of each strain $\left(\mathrm{OD}_{600} 0.5\right)$ was separately inoculated in $100 \mathrm{~mL}$ Erlenmeyer flask containing $40 \mathrm{~mL}$ YPD broth and fermented at $30^{\circ} \mathrm{C}$ in shake rotary revolving at $170 \mathrm{rpm}$. The $100 \mathrm{uL}$ sample of each strain was collected after an interval of $3 \mathrm{~h}, 6 \mathrm{~h}, 12 \mathrm{~h}, 24 \mathrm{~h}, 36 \mathrm{~h}, 48 \mathrm{~h}, 60 \mathrm{~h}, 72 \mathrm{~h}$, and $80 \mathrm{~h}$. Later, each sample was centrifuged at $5000 \mathrm{~g}$ for $1 \mathrm{~min}$, and the production of ethanol in FSE, FSE1, and WS strains was measured using SBA-40E biosensor (Institute of Biology, Shandong Academy of Sciences, China). All experiments were performed in biological triplicate.

\section{Conclusions}

Findings of this study display that ligation of transcription factor binding sites (TFBS) from strong promoters upstream of yeast promoters increased the strength of native promoters. Engineered promoters were employed to co-overexpress the squalene and ethanol production pathways in S. cerevisiae. Employment of metal ion repressible promoters downregulated the expression of ERG1 and enhanced the production of squalene up to $255.11 \mathrm{mg} / \mathrm{L}$ in FSE strain. Co-overexpression of squalene and ethanol pathways enabled the co-production of squalene and ethanol up to $255.11 \mathrm{mg} / \mathrm{L}$ and $40.2 \mathrm{mg} / \mathrm{L}$, respectively, in FSE1 strain. Moreover, FSE1 strain synergistically downregulated the expression of the fusel alcohol pathway, perhaps to divert the metabolic flux toward engineered pathways. It is assumed that FSE1 strain downregulated the expression of the fusel alcohol pathway by downregulating the expression of GCN4.

Our prospective study will focus on the identification and characterization of vital components of regulatory networks associated with GCN4 based regulation of fusel alcohol pathway.

Supplementary Materials: The following are available online at http://www.mdpi.com/2218-1989/10/2/56/s1, Figure S1: Work flow of characterization of strength of engineered and repressible promoters; Figure S2: Design of the module used to overexpress the DGA1 in engineered strain FSE; Figure S3: Design of the module used to swipe the ERG1 promoter with AFT1p and CTR1p in engineered strain FSE; Figure S4: Nile red staining dye was used to visualize the lipid droplets biogenesis and accumulation of squalene in engineered strain FSE compared with wild strain; Figure S5: (a) Confocal microscopic analysis of wild type yeast promoters. (b) Confocal microscopic analysis of engineered promoters containing TFBS of HHF2p; Figure S6: GCMS analysis of metabolites; Table S1a: List of the primers designed to amplify and construct the engineered promoters; Table S1b: List of the primers designed to amplify the metal ions repressible promoters; Table S2: List of primer designed to amplify the genes of module-1; Table S3: List of primer designed for qRT-PCR of overexpressed genes of the squalene biosynthesis pathway, ethanol production pathway and fusel alcohol pathway; Table S4: List of primer designed to amplify the DNA fragments for modules given in supplementary Figure S1; Table S5: List of primer designed to amplify the DNA fragments of DGA1 module; Table S6: Fluorescence intensity of wild type promoters and engineered promoters.

Author Contributions: Conceptualization, R.M.; Data curation, A.N. and I.K.; Formal analysis, U.K., M.U.F.A., U.I., I.K. and A.R.; Funding acquisition, I.K.; Investigation, N.R. and U.K.; Methodology, R.M.; Project administration, M.A.; Writing—original draft, R.M. and A.R.; Writing—review \& editing, N.R., B.H.K., Y.R., H.K., Y.R. and A.R. All authors have read and agreed to the published version of the manuscript.

Funding: This study was supported by the National Natural Science Foundation of China (No. U1632264) and the Higher Education Commission of Pakistan (No. SGR 5550).

Acknowledgments: We are very thankful to Li Chun and his team for support. 
Conflicts of Interest: All authors have no conflict of interest.

\section{References}

1. Smith, T.J. Squalene: Potential chemopreventive agent, Expert Opin. Investig. Drugs. 2000, 9, $1841-1848$. [CrossRef]

2. Nakazawa, A.; Kokubun, Y.; Matsuura, H.; Yonezawa, N.; Kose, R.; Yoshida, M.; Tanabe, Y.; Kusuda, E.; Van Thang, D.; Ueda, M.; et al. TLC screening of thraustochytrid strains for squalene production. J. Appl. Phycol. 2014, 26, 29-41. [CrossRef]

3. Ahmed, M.S.; Ikram, S.; Rasool, A.; Li, C. Design and construction of short synthetic terminators for B-amyrin production in Saccharomyces cerevisiae. Biochem. Eng. J. 2019, 105-116. [CrossRef]

4. Kirby, J.; Romanini, D.W.; Paradise, E.M.; Keasling, J.D. Engineering triterpene production in Saccharomyces cerevisiae- $\beta$-amyrin synthase from Artemisia annua. FEBS J. 2008, 275, 1852-1859. [CrossRef] [PubMed]

5. Kohno, Y.; Egawa, Y.; Itoh, S.; Nagaoka, S.; Takahashi, M.; Mukai, K. Kinetic study of quenching reaction of singlet oxygen and scavenging reaction of free radical by squalene in $\mathrm{n}$-butanol, Biochim. Biophys. Acta (BBA)/Lipids Lipid Metab. 1995, 1256, 52-56. [CrossRef]

6. Amarowicz, R. Squalene: A natural antioxidant? Eur. J. Lipid Sci. Technol. 2009, 111, 411-412. [CrossRef]

7. Aguilera, Y.; Dorado, M.E.; Prada, F.A.; Martínez, J.J.; Quesada, A.; Ruiz-Gutiérrez, V. The protective role of squalene in alcohol damage in the chick embryo retina. Exp. Eye Res. 2005, 80, 535-543. [CrossRef]

8. Storm, H.M.; Oh, S.Y.; Kimler, B.F.; Norton, S. Radioprotection of mice by dietary squalene. Lipids 1993, 28, 555-559. [CrossRef]

9. Hernández-Pérez, M.; Rabanal Gallego, R.M.; Pascual Alayón, P.J.; Brito Hernández, A. Squalene content in livers from deep-sea sharks caught in Canary Island waters. Mar. Freshw. Res. 1997, 48, 573-576. [CrossRef]

10. Techera, E.J.; Klein, N. Sharks: Conservation, governance and management; Earthscan: London, UK, 2014. [CrossRef]

11. Clarke, S. Shark product trade in Hong Kong and mainland China and implementation of the CITES shark listings; TRAFFIC East Asia: Hong Kong, China, 2004.

12. Spanova, M.; Czabany, T.; Zellnig, G.N.; Leitner, E.; Hapala, I.; Daum, G.N. Effect of lipid particle biogenesis on the subcellular distribution of squalene in the yeast Saccharomyces cerevisiae. J. Biol. Chem. 2010, 285, 6127-6133. [CrossRef]

13. Spanova, M.; Zweytick, D.; Lohner, K.; Klug, L.; Leitner, E.; Hermetter, A.; Daum, G. Influence of squalene on lipid particle/droplet and membrane organization in the yeast Saccharomyces cerevisiae. Biochim. Biophys. Acta - Mol. Cell Biol. Lipids. 2012, 1821, 647-653. [CrossRef] [PubMed]

14. Rasool, A.; Zhang, G.; Li, Z.; Li, C. Engineering of the terpenoid pathway in Saccharomyces cerevisiae co-overproduces squalene and the non-terpenoid compound oleic acid. Chem. Eng. Sci. 2016, 152, 457-467. [CrossRef]

15. Rasool, A.; Ahmed, M.S.; Li, C. Overproduction of squalene synergistically downregulates ethanol production in Saccharomyces cerevisiae. Chem. Eng. Sci. 2016, 152, 370-380. [CrossRef]

16. Hull, C.M.; Loveridge, E.J.; Rolley, N.J.; Donnison, I.S.; Kelly, S.L.; Kelly, D.E. Co-production of ethanol and squalene using a Saccharomyces cerevisiae ERG1 (squalene epoxidase) mutant and agro-industrial feedstock. Biotechnol. Biofuels. 2014, 7. [CrossRef] [PubMed]

17. McGovern, P.E.; Zhang, J.; Tang, J.; Zhang, Z.; Hall, G.R.; Moreau, R.A.; Nuñez, A.; Butrym, E.D.; Richards, M.P.; Wang, C.S.; et al. Fermented beverages of pre- and proto-historic China. Proc. Natl. Acad. Sci. USA 2004, 101, 17593-17598. [CrossRef] [PubMed]

18. Hazelwood, L.A.; Daran, J.M.; Van Maris, A.J.A.; Pronk, J.T.; Dickinson, J.R. The Ehrlich pathway for fusel alcohol production: A century of research on Saccharomyces cerevisiae metabolism. Appl. Environ. Microbiol. 2008, 74, 2259-2266. [CrossRef]

19. Ishida, N.; Saitoh, S.; Onishi, T.; Tokuhiro, K.; Nagamori, E.; Kitamoto, K.; Takahashi, H. The effect of pyruvate decarboxylase gene knockout in Saccharomyces cerevisiae on L-lactic acid production. Biosci. Biotechnol. Biochem. 2006. [CrossRef]

20. Yu, T.; Zhou, Y.J.; Huang, M.; Liu, Q.; Pereira, R.; David, F.; Nielsen, J. Reprogramming Yeast Metabolism from Alcoholic Fermentation to Lipogenesis. Cell 2018. [CrossRef] 
21. Koopman, F.; Beekwilder, J.; Crimi, B.; van Houwelingen, A.; Hall, R.D.; Bosch, D.; van Maris, A.J.A.; Pronk, J.T.; Daran, J.M. De novo production of the flavonoid naringenin in engineered Saccharomyces cerevisiae. Microb. Cell Fact. 2012. [CrossRef]

22. Blazeck, J.; Garg, R.; Reed, B.; Alper, H.S. Controlling promoter strength and regulation in Saccharomyces cerevisiae using synthetic hybrid promoters. Biotechnol. Bioeng. 2012, 109, 2884-2895. [CrossRef]

23. McNerney, M.P.; Styczynski, M.P. Precise control of lycopene production to enable a fast-responding, minimal-equipment biosensor. Metab. Eng. 2017. [CrossRef] [PubMed]

24. Englund, E.; Liang, F.; Lindberg, P. Evaluation of promoters and ribosome binding sites for biotechnological applications in the unicellular cyanobacterium Synechocystis sp. PCC 6803. Sci. Rep. 2016, 6. [CrossRef] [PubMed]

25. Ma, S.M.; Garcia, D.E.; Redding-Johanson, A.M.; Friedland, G.D.; Chan, R.; Batth, T.S.; Haliburton, J.R.; Chivian, D.; Keasling, J.; Petzold, C.J.; et al. Optimization of a heterologous mevalonate pathway through the use of variant HMG-CoA reductases. Metab. Eng. 2011. [CrossRef]

26. Segall-Shapiro, T.H.; Sontag, E.D.; Voigt, C.A. Engineered promoters enable constant gene expression at any copy number in bacteria. Nat. Biotechnol. 2018, 36, 352-358. [CrossRef]

27. Johnson, A.O.; Gonzalez-Villanueva, M.; Tee, K.L.; Wong, T.S. An Engineered Constitutive Promoter Set with Broad Activity Range for Cupriavidus necator H16. ACS Synth. Biol. 2018, 7, 1918-1928. [CrossRef]

28. Lee, K.S.; Kim, J.S.; Heo, P.; Yang, T.J.; Sung, Y.J.; Cheon, Y.; NKoo, H.M.; Yu, B.J.; Seo, J.H.; Jin, Y.S.; et al. Characterization of Saccharomyces cerevisiae promoters for heterologous gene expression in Kluyveromyces marxianus. Appl. Microbiol. Biotechnol. 2013. [CrossRef]

29. Redden, H.; Alper, H.S. The development and characterization of synthetic minimal yeast promoters. Nat. Commun. 2015. [CrossRef]

30. Biggs, B.W.; Lim, C.G.; Sagliani, K.; Shankar, S.; Stephanopoulos, G.; De Mey, M.; Ajikumar, P.K. Overcoming heterologous protein interdependency to optimize P450-mediated Taxol precursor synthesis in Escherichia coli. Proc. Natl. Acad. Sci. USA 2016. [CrossRef]

31. Minkenberg, B.; Wheatley, M.; Yang, Y. CRISPR/Cas9-Enabled Multiplex Genome Editing and Its Application. Prog. Mol. Biol. Transl. Sci. 2017, 111-132. [CrossRef]

32. Paradise, E.M.; Kirby, J.; Chan, R.; Keasling, J.D. Redirection of flux through the FPP branch-point in saccharomyces cerevisiae by down-regulating squalene synthase. Biotechnol. Bioeng. 2008, 100, 371-378. [CrossRef]

33. Berthelet, S.; Usher, J.; Shulist, K.; Hamza, A.; Maltez, N.; Johnston, A.; Fong, Y.; Harris, L.J.; Baetz, K. Functional genomics analysis of the Saccharomyces cerevisiae iron responsive transcription factor Aft1 reveals iron-independent functions. Genetics 2010, 185, 1111-1128. [CrossRef] [PubMed]

34. Dancis, A.; Haile, D.; Yuan, D.S.; Klausner, R.D. The Saccharomyces cerevisiae copper transport protein (Ctr1p). Biochemical characterization, regulation by copper, and physiologic role in copper uptake. J. Biol. Chem. 1994, 269, 25660-25667. [PubMed]

35. Dai, Z.; Liu, Y.; Huang, L.; Zhang, X. Production of miltiradiene by metabolically engineered Saccharomyces cerevisiae. Biotechnol. Bioeng. 2012, 109, 2845-2853. [CrossRef] [PubMed]

36. Westfall, P.J.; Pitera, D.J.; Lenihan, J.R.; Eng, D.; Woolard, F.X.; Regentin, R.; Horning, T.; Tsuruta, H.; Melis, D.J.; Owens, A.; et al. Production of amorphadiene in yeast, and its conversion to dihydroartemisinic acid, precursor to the antimalarial agent artemisinin. Proc. Natl. Acad. Sci. USA 2012, 109. [CrossRef]

37. Scalcinati, G.; Knuf, C.; Partow, S.; Chen, Y.; Maury, J.; Schalk, M.; Daviet, L.; Nielsen, J.; Siewers, V. Dynamic control of gene expression in Saccharomyces cerevisiae engineered for the production of plant sesquitepene $\alpha$-santalene in a fed-batch mode. Metab. Eng. 2012, 14, 91-103. [CrossRef]

38. Moses, T.; Pollier, J.; Almagro, L.; Buyst, D.; Van Montagu, M.; Pedreño, M.A.; Martins, J.C.; Thevelein, J.M.; Goossens, A. Combinatorial biosynthesis of sapogenins and saponins in Saccharomyces cerevisiae using a C-16 $\alpha$ hydroxylase from Bupleurum falcatum. Proc. Natl. Acad. Sci. USA 2014, 111, 1634-1639. [CrossRef]

39. Albertsen, L.; Chen, Y.; Bach, L.S.; Rattleff, S.; Maury, J.; Brix, S.; Nielsen, J.; Mortensen, U.H. Diversion of flux toward sesquiterpene production in Saccharomyces cerevisiae. Appl. Environ. Microbiol. 2011, 77, 1033-1040. [CrossRef]

40. BLOCH, K. Biological synthesis of cholesterol. Harvey Lect. 1952, 48, 68-88. [CrossRef] 
41. Donald, K.A.G.; Hampton, R.Y.; Fritz, I.B. Effects of overproduction of the catalytic domain of 3-hydroxy-3methylglutaryl coenzyme A reductase on squalene synthesis in Saccharomyces cerevisiae. Appl. Environ. Microbiol. 1997, 63, 3341-3344. [CrossRef]

42. Farhi, M.; Marhevka, E.; Masci, T.; Marcos, E.; Eyal, Y.; Ovadis, M.; Abeliovich, H.; Vainstein, A. Harnessing yeast subcellular compartments for the production of plant terpenoids. Metab. Eng. 2011, 13, 474-481. [CrossRef]

43. Venugopal, V.; Kumaran, A.K.; Sekhar Chatterjee, N.; Kumar, S.; Kavilakath, S.; Nair, J.R.; Mathew, S. Biochemical Characterization of Liver Oil of Echinorhinus brucus (Bramble Shark) and Its Cytotoxic Evaluation on Neuroblastoma Cell Lines (SHSY-5Y). Scientifica (Cairo) 2016. [CrossRef]

44. Wei, L.J.; Kwak, S.; Liu, J.J.; Lane, S.; Hua, Q.; Kweon, D.H.; Jin, Y.S. Improved squalene production through increasing lipid contents in Saccharomyces cerevisiae. Biotechnol. Bioeng. 2018. [CrossRef] [PubMed]

45. Jackson, C.L. Lipid droplet biogenesis. Curr. Opin. Cell Biol. 2019. [CrossRef] [PubMed]

46. Adeyo, O.; Horn, P.J.; Lee, S.K.; Binns, D.D.; Chandrahas, A.; Chapman, K.D.; Goodman, J.M. The yeast lipin orthologue Pah1p is important for biogenesis of lipid droplets. J. Cell Biol. 2011. [CrossRef] [PubMed]

47. Radulovic, M.; Knittelfelder, O.; Cristobal-Sarramian, A.; Kolb, D.; Wolinski, H.; Kohlwein, S.D. The emergence of lipid droplets in yeast: Current status and experimental approaches. Curr. Genet. 2013. [CrossRef] [PubMed]

48. Long, A.; Manneschmidt, A.; Dortch, R.; Verbruggie, R.; Dalhaimer, P. The Number of Lipid Droplets in the Fission Yeast $\mathrm{S}$. pombe is a Function of the Cell Cycle Stage. Biophys. J. 2011. [CrossRef]

49. Ma, T.; Shi, B.; Ye, Z.; Li, X.; Liu, M.; Chen, Y.; Xia, J.; Nielsen, J.; Deng, Z.; Liu, T. Lipid engineering combined with systematic metabolic engineering of Saccharomyces cerevisiae for high-yield production of lycopene. Metab. Eng. 2019. [CrossRef]

50. Natunen, K.; Seppälä, J.; Schwenk, D.; Rischer, H.; Spilling, K.; Tamminen, T. Nile Red staining of phytoplankton neutral lipids: species-specific fluorescence kinetics in various solvents. J. Appl. Phycol. 2015. [CrossRef]

51. Ruckenstuhl, C.; Lang, S.; Poschenel, A.; Eidenberger, A.; Baral, P.K.; Kohút, P.; Hapala, I.; Gruber, K.; Turnowsky, F. Characterization of squalene epoxidase of Saccharomyces cerevisiae by applying terbinafine-sensitive variants. Antimicrob. Agents Chemother. 2007. [CrossRef]

52. Van Maris, A.J.A.; Geertman, J.M.A.; Vermeulen, A.; Groothuizen, M.K.; Winkler, A.A.; Piper, M.D.W.; Van Dijken, J.P.; Pronk, J.T. Directed Evolution of Pyruvate Decarboxylase-Negative Saccharomyces cerevisiae, Yielding a C2-Independent, Glucose-Tolerant, and Pyruvate-Hyperproducing Yeast. Appl. Environ. Microbiol. 2004. [CrossRef]

53. Drewke, C.; Ciriacy, M. Overexpression, purification and properties of alcohol dehydrogenase IV from Saccharomyces cerevisiae. BBA - Gene Struct. Expr. 1988, 950, 54-60. [CrossRef]

54. Raj, S.B.; Ramaswamy, S.; Plapp, B.V. Yeast Alcohol Dehydrogenase Structure and Catalysis. Biochemistry 2014, 53, 5791-5803. [CrossRef] [PubMed]

55. Ljungdahl, P.O.; Daignan-Fornier, B. Regulation of amino acid, nucleotide, and phosphate metabolism in Saccharomyces cerevisiae. Genetics 2012, 190, 885-929. [CrossRef] [PubMed]

56. Eriksson, P.R.; Mendiratta, G.; McLaughlin, N.B.; Wolfsberg, T.G.; Marino-Ramirez, L.; Pompa, T.A.; Jainerin, M.; Landsman, D.; Shen, C.-H.; Clark, D.J. Global Regulation by the Yeast Spt10 Protein Is Mediated through Chromatin Structure and the Histone Upstream Activating Sequence Elements. Mol. Cell. Biol. 2005. [CrossRef] [PubMed]

57. Arndt, K.; Fink, G.R. GCN4 protein, a positive transcription factor in yeast, binds general control promoters at all 5' TGACTC $3^{\prime}$ sequences. Proc. Natl. Acad. Sci. USA 1986. [CrossRef] [PubMed]

58. Randise-Hinchliff, C.; Brickner, J.H. Transcription factors dynamically control the spatial organization of the yeast genome. Nucleus 2016. [CrossRef]

59. Shao, Z.; Zhao, H.; Zhao, H. DNA assembler, an in vivo genetic method for rapid construction of biochemical pathways. Nucleic Acids Res. 2009. [CrossRef]

60. Krogh, B.O.; Symington, L.S. Recombination Proteins in Yeast. Annu. Rev. Genet. 2004, 38, $233-271$. [CrossRef] 
61. Jasin, M.; Rothstein, R. Repair of strand breaks by homologous recombination. Cold Spring Harb. Perspect. Biol. 2013. [CrossRef]

62. Alemán-Nava, G.S.; Cuellar-Bermudez, S.P.; Cuaresma, M.; Bosma, R.; Muylaert, K.; Ritmann, B.E.; Parra, R. How to us Nile Red, a selective fluorescent stain for microalgal neutral lipids. J. Microbiol. Methods. 2016. [CrossRef] 